\title{
The Timing of Births: A Marriage Market Analysis *
}

\author{
Elizabeth M. Caucutt \\ Nezih Guner \\ Department of Economics, \\ Department of Economics, \\ University of Rochester. \\ Pennsylvania State University. \\ John Knowles \\ Department of Economics, \\ University of Pennsylvania.
}

October 1, 2001

\begin{abstract}
We argue that one of the key channels linking the labor and marriage markets is the decision of when to become a parent. We develop an equilibrium model of marriage, divorce, and human capital accumulation that allows for differential timing of fertility. We calibrate the model to US panel data and analyze the effects of raising women's wages relative to men's, and increasing the rate of return to experience for women. We find that an increase in the returns to experience for women is causes an increase in fraction of children born to women over age 30, and that raising women's wages reduces marriage rates.
\end{abstract}

*Elizabeth M. Caucutt: Department of Economics, University of Rochester, Rochester, NY 14627. e-mail: ecau@troi.cc.rochester.edu. Nezih Guner: Department of Economics, Kern Graduate Building, Pennsylvania State University, University Park, PA 16802. e-mail: nguner@psu.edu. John Knowles: Department of Economics, 3718 Locust Walk, University of Pennsylvania, Philadelphia, PA 19104. email: knowles@econ.sas.upenn.edu. The second author acknowledges financial support from the Social Sciences and Humanities Research Council of Canada. 


\section{Introduction}

Two of the most remarkable trends in family life of the last 40 years have been the decline of marriage and the rise in labor force participation of young women. Despite a constant stream of empirical research, there remain many open questions concerning the origins of, and connections between, these phenomena. This is due partly to the specialization of most research into demographic versus labor market analysis, despite Becker's seminal work on marriage [Becker $(1973,74)]$, in which marriage and labor markets are definitively linked through the comparative advantage of spouses in market vs. non-market labor. In this paper, we argue that one of the key channels linking the two markets is the decision of when to become a parent, and that this margin has important implications for the evolution of income inequality.

Becker's theory defines marriage as an arrangement for non-market transactions, and the center piece of his view of marriage is the production of children; most other transactions associated with marriage, regarding sex, household upkeep and the like could be provided for in the market, but the production of one's own children, Becker calls the distinguishing characteristic of marriage. ${ }^{1}$ One might expect, given this view, that research into women's labor-force behavior would be centered on marriage decisions and on parental decisions regarding such matters as when to have children, and how many, and how much to invest in their education. However most empirical literature on the labor market takes as given the demographic features of households. Furthermore analyses that do incorporate marriage decisions tend to take as given the state of the marriage market, in terms of the distribution of potential spouses with respect to education and wages.

By contrast, our paper follows in a recent tradition that attempts to unite family and labor market decisions on the one hand with the evolution over time of the marriage and labor markets on the other. In this paper, we develop an equilibrium model of family dynamics, labor supply and the distribution of income across households. As in Aiyagari, Greenwood and Guner (2000), the marriage market evolves in response to parental decisions regarding marriage and divorce. As in Knowles (1998) and Greenwood, Guner and Knowles(2000) and Regalia and Rios-Rull (1999), parents choose fertility and investment in children's human capital, decisions which will influence the marriage market in the fol-

\footnotetext{
${ }^{1}$ Becker writes: "Nothing distinguishes married households more from single households...than the presence, even indirectly, of children".
} 
lowing generation. Parents also choose when to have children; this matters for two basic reasons. First women who have children earlier have less opportunity to develop human capital, and second because the proportion of children from poor families increases more rapidly because they reproduce at an earlier age. Women with low human capital in our model tend to have children earlier for the same reason that they tend to have more children: the opportunity cost of time spent raising children is lower because these women have lower wages. Furthermore, when wages increase with labor-market experience, women who plan to spend more time in the labor market will have the strongest incentives to delay fertility.

Empirically, two basic facts suggest the hypothesis that the timing channel plays an important role in the changes alluded to above. First, we know that women in lowincome households tend to have children earlier than women in higher-income households. In this paper we demonstrate this in the Panel Study of Income Dynamics using measures of lifetime income, but this has previously been shown, for annual income measures, by Conesa (1999). Second, we know that on average women are now having children later than they did 30 years ago For white women, the probability of a first birth at age 20 has fallen from $17 \%$ in 1960 to $7 \%$ in the late 1980 (Hotz et. al.,1997). Between 1975 and 1993, the fraction of total fertility rate accounted by women in their thirties increased from about 20\% to $28 \%$ (Morgan,1996). By 1996, this number had increased to $31 \%$.

Empirical studies suggest that such patterns are strongly linked to human capital accumulation. The time a mother spends on child care and the number of young children she has substantially reduce her labor force participation, according to studies by Hotz and Miller (1988) and Eckstein and Wolpin (1989). Lower and interrupted participation rates lead to lower human capital accumulation and lower wages for females, according to Altug and Miller (1998) and Gunderson (1989). Waldfogel (1998) finds that in 1994, mean wages for women with no children were $81.3 \%$ of mean wages for men, while mean wages for married mothers were only $76.5 \%$ of mean wages for men. Finally, the spread in childbearing ages across education groups has been increasing dramatically; Rindfuss, Morgan and Offutt (1996) report that over the period 1963-1989 it was women with college degrees who shifted their child-bearing the most towards later ages, confirming a trend noticed earlier by Mare(1995) and Lewis and Ventura (1990). It is instructive to note that this evolution of fertility timing is not simply a composition effect; these latter results imply 
significant changes in behavior within education groups.

It is difficult to infer from empirical work alone how important the timing margin is in a quantitative sense; by abstracting from such variation in timing, is the equilibrium inequality literature missing a significant piece of the story regarding family formation, women's labor force participation and investment in human capital? To explore the importance of the timing channel, we perform computational experiments on a calibrated version of the model. We calibrate the model so that the steady-state equilibrium exhibits the features of the United States data that are most relevant for studying female labor supply, such as higher fertility, higher fraction of single mothers and earlier parenthood among poor women. The calibrated model allows us to run experiments that are intended to reflect the types of changes observed in the United States over the last few decades, such as raising women's wages relative to men's wages, and increasing the rate of return to labor-market experience for women, and to interpret the results quantitatively. The previous literature in this area tends to abstract from the timing aspect of fertility, with a few exceptions. Conesa (1999) and Mullin and Wang (2001) construct general equilibrium models of the timing of fertility with educational attainment and human capital accumulation, but both ignore marriage dynamics.

We find that allowing for choice in the timing of fertility has interesting implications for the effects of such changes in the long run. A rise in the returns to experience results in the following types of changes that are similar to the experience of the United States since the 1970s: 1) a higher proportion of kids are born to parents in the second period of their fertile lives, 2) the age-earnings profile for married women becomes steeper and 3) income increases more for female-headed households compared to married couple households.

In contrast, a decline in the gender gap in wages has a only small effect on the timing of births, while it has a comparatively large effect on marital status; the fraction of population that is married declines, again consistent with what we observe in the data since the 1970s. The reason is that fertility reduces the mother's labor supply, so women have fewer children when their wages are higher, reducing the gains from marriage. The equilibrium in the marriage market shifts towards single parent outcomes, and children of single parents tend to have lower human capital, an effect that is well-documented in the empirical literature (see Gruber (2000) for a recent review of the evidence regarding children of divorced parents). 
There are two main channels by which the timing margin in our model affects the distribution of income: 1)Parents with low earnings will tend to have kids earlier, so the mass of their descendants will grow more quickly over time. 2) Delaying fertility increases the human capital of the kids. Conversely, the income distribution affects the decisionmaking of agents in two basic ways: 1) an agent's marital decisions will depend on his or her expectations of future matches, and thus on the distribution of agents of the opposite sex. 2) Household decisions will depend on the bargaining power of each spouse, which depends in turn on the state of the marriage and labor markets. With our model it is possible to compute rough estimates of the quantitative importance of these channels. We find that suppressing the bargaining power effect, for instance, reduces greatly the effect on the timing of fertility of a change in women's returns to experience. Suppressing changes in the human capital distribution has relatively small effects, but this is because of the existence of off-setting forces.

Our results complement those of Olivetti (2000) who models the labor-supply responses of women to shifts in the wage gap and returns to experience, taking demographics as given. She finds that a simple wage shift cannot account for the increase in labor supply of young married women, while the shift in returns to women's experience can, a finding analogous to our own regarding marriage and fertility timing.

In the next section, we explore empirically the issues raised above using the Panel Study of Income Dynamics (PSID). We develop our model in the succeeding two sections, first describing the environment, and then the equilibrium. In Section 5 we describe how the model is calibrated to reproduce those features of US data that we identified as most relevant for the quantitative analysis. The results for our benchmark model are reported in Section 6 and the computational experiments in Section 7. Our conclusions are listed in the final section.

\section{Labor Supply, Marital Status and Fertility Dynamics in the PSID}

In this section we report statistics for labor supply and family decisions by marital status, cohort, age and labor income of men and women. These statistics are based on a simple 
analysis of the Panel Study of Income Dynamics from 1968 to 1997. We use this analysis to provide a baseline for evaluating our model, and illustrate how the timing of fertility varies over recent cohorts and across the household income distribution.

Our sample is drawn from the cross-sectional sample of the PSID, and hence is a representative random sample of the population in 1967 . We select men and women for whom marriage data is reasonably complete. ${ }^{2}$ Marriages are taken by the PSID to refer to both formal marriage and to domestic partner arrangements.

For marriage data that pertains to the time interval covered by the surveys, we take the beginning and ending dates of marriages directly from the married-pairs variable for that year; marriages are deemed to being in the first year where the variable is non-zero, and the marriage ends in the first year for which the variable is zero. ${ }^{3}$ For marriages that pre-date the survey, we use the reported variables for the beginning and ending of each marriage. This is mainly relevant for determining the initial condition of older people at the beginning of the survey, and for reporting marriage ages and single-motherhood.

In Table 1, we rank women by the predicted present value of labor income of their household over ages 30-70. The predicted income in each year is obtained by a fixed-effects regression, as described in Knowles (1998). The units are 1967 dollars. The table shows that women in the lowest income quintile have their first child at age 20.9 on average, compared to age 24.5 for the richest quintile. The probability that women have children before age 20 is 0.46 for the poorest, compared to 0.22 for the richest women. The richer women are also more likely to have children after age 30; 0.45 compared to 0.37 children for the poorest mothers on average. Thus the overall pattern is one of much later child-bearing for higher income women. The table also shows that poorer women are much more likely to be single or divorced mothers than richer women. This reflects the fact shown in the last two columns, that poorer women are more likely to divorce earlier.

In Figure 1, we see the proportion of women who become mothers by age 20, by birth cohort. It is clear from the diagram that this statistic has been climbing steadily since the 1923-27 cohort, but that a dramatic decline has set in since the 1947 cohort. This decline is of the same order of magnitude as the fluctuations earlier (the 1918 cohort for

\footnotetext{
${ }^{2}$ For some analyses, the sample was restricted to people who reported two marriages or fewer, as beginning and ending dates of marriages were generally available only for first and last marriages.

${ }^{3}$ Thus people who shuttle directly from one marriage to another without an intervening single period are considered continuously married.
} 
instance) that may have been related to World War 2. The diagram also shows that other measures of the timing of fertility display a similar pattern. The age at which women first become mothers has increased over the last three cohorts, while both the probability that first birth occurs when the mother is aged 20 and the proportion of kids born by the time the mother has reached age 20 have fallen.

In Table 2, we take a closer look at the two most recent cohorts. We see that the age at first becoming a mother increased from 21.8 to 22.0 years, and that the proportion of women who became mothers by age 20 fell from 0.4 to 0.32 . The proportion of women who had no children by age 40 increased, as did the proportion of children born when their mothers were older than 30 , which went from 0.36 to 0.4 .

In Table 3, we answer the following counterfactual timing statistics: 1) Suppose the fertility behavior had remained constant, and that education choices of the 1950's cohort had evolved to match that of the 1960's cohort. 2) Suppose that education choices had remained the same, but fertility behavior had evolved to match that of the 60's. The first part of table gives the timing statistics by years of education. The second part gives the counterfactuals. We see that the average age of becoming a mother is roughly the same under each counterfactual. This means that about half of the actual change is due to education choice. The proportion of kids born after age 30 on the other hand is much higher for the second-counter factual. This means that most of the change is due to fertility behavior changes within education groups.

Turning to the labor market, we show in the next few tables the relations between marital status by cohort and earnings and hours of labor supply. Because the model necessarily abstracts from the full richness of the life cycle, calibration of the model requires that we compress the annual life-cycle data into a few periods, which we set to 10 years duration, as described below. Marital status is divided into three categories: "single", which is taken to mean never married, "married", which means living with a spouse, and "divorced", which means previously married. Tables 4a-b show that married women work much less than single women before age 30, but in the most recent cohort work a similar number of hours after age 30. One striking fact is that this recovery in married women's hours was not apparent in the older cohort. If we assume that the total time endowment is 5000 hours per year, then the older cohort of women spends roughly $25 \%$ of their time working when single, and $20 \%$ when married. Analogous figures for men are shown in Table 
5a-b. Men work around 2000 hours per year, except for singles, who tend to work about 1800 hours

Family income is of course much higher for married women than for single or divorced. Tables $3 \mathrm{a}-\mathrm{b}$ show that the ratio is about $40 \%$ for younger women and drops to around $30 \%$ for women in their 30's. For men, the differential is $65 \%$ for the young cohort in their 20's, and 50\% for older men. If one ignores other family income, which includes non-labor income, transfers and labor income of other household members, then the labor income of single men is in the range of $60 \%-80 \%$ of that of the married couples. For women in their 20's, earnings of singles are about $30 \%$ of the married couple's labor income, but for older women this ratio drops to the $20-25 \%$ range.

To summarize, the essential features of the data are that poorer women tend to have children much earlier than richer women, whether measured by average age at first becoming a mother or percentage of kids born after age 30, that married women work much less than single women, and that parents in the most recent cohorts tend to have children later than those in earlier cohorts.

\section{Model}

\subsection{Economic Environment}

The economy is populated by people who live for five periods, two periods as children and three periods as adults. Adults differ in their gender, productivity, marital status, employment and child bearing histories. Women can have children in the first two periods of their adult life. The children are attached to their mother throughout their two-period childhood and they make no economic decisions. Adults care about consumption, human capital investment in their children, and leisure.

Each period there is a marriage market where single agents meet. Each single agent takes a draw from this market. Every period, already married couples decide whether or not to stay married. If they divorce they are considered single and can have an immediate draw from the marriage market. The marriage market only matches single men and women from the same generation. For simplicity we allow every male an equal chance of being matched with any given female.

Each period, one and two-period old married couples and single women decide how 
many kids, $k$, to have. We will restrict this choice to $k \in\{0,1, \ldots, \bar{k}\}$. Children have a fixed time cost for their parents. This cost depends on the age of the child and on the gender of the parent. Let $k_{1}$ represent the number of kids who are one-period old and $k_{2}$ represent the number of kids who are two-periods old. The total number of kids in a household is given by $k=k_{1}+k_{2}$. Only two-period old women can have children of different ages. When there is no confusion we will use $k$ to represent the number of kids of any age.

Let $x$ denote the productivity of a female, and $z$ the productivity of a male. Furthermore, assume that

$$
x \in\left\{x_{1}, \ldots, x_{N}\right\} \text { and } z \in\left\{z_{1}, \ldots, z_{N}\right\}
$$

Each period the oldest generation of children become young adults, replacing the oldest generation of adults. The productivity of a first period adult depends on the total human capital investment he or she receives during childhood. The productivity of a second period adult depends on his or her initial productivity and labor supply in the first period. This captures the observation that past labor supply affects current wages. Similarly, the productivity of a third period adult depends on his or her productivity and labor supply in the second period. The fact that future productivity depends on current labor supply decisions is key to the hypothesis that a change in the returns to labor market experience for women has led to a shift in the timing of births.

Females have the following utility functions

$$
F\left(c, h, k_{1}, k_{2}, 1-l-t-\chi_{f}\left(k_{1}, k_{2}\right)\right)=\frac{c^{\nu}}{\nu}+w \frac{k^{\xi}}{\xi} \frac{h^{\vartheta}}{\vartheta}+\delta \frac{\left(1-l-t-\chi_{f}\left(k_{1}, k_{2}\right)\right)^{\varsigma}}{\varsigma}-\gamma
$$

where $c$ is consumption, $h$ is human capital investment in children, $l$ is labor supply, $t$ is child care, $\gamma$ is a marriage match quality shock, and $\chi_{f}\left(k_{1}, k_{2}\right)$ is the fixed time cost of having $k_{1}$ one-period old and $k_{2}$ two-period old children at home. The function $\frac{k^{\xi}}{\xi}$ represents the utility a female gets from having $k=k_{1}+k_{2}$ kids at home, while function $\frac{h^{\vartheta}}{\vartheta}$ gives the utility from the quality of those children. Moreover, let

$$
\chi_{f}\left(k_{1}, k_{2}\right)=\chi_{f}^{1} k_{1}+\chi_{f}^{2} k_{2}
$$

Similarly, for males

$$
M\left(c, h, k_{1}, k_{2}, 1-n-\chi_{m}\left(k_{1}, k_{2}\right)\right)=\frac{c^{\nu}}{\nu}+w \frac{k^{\xi}}{\xi} \frac{h^{\vartheta}}{\vartheta}+\delta \frac{\left(1-n-\chi_{m}\left(k_{1}, k_{2}\right)\right)^{\varsigma}}{\varsigma}-\gamma
$$


where $n$ is labor supply, and

$$
\chi_{m}\left(k_{1}, k_{2}\right)=\chi_{m}^{1} k_{1}+\chi_{m}^{2} k_{2}
$$

For a single male $\frac{h^{\vartheta}}{\vartheta}$ and $\chi_{m}\left(k_{1}, k_{2}\right)$ are zero.

The total income of a household is given by

$$
Y(x, z, l, n)=x l+z n .
$$

Per member consumption is then given by

$$
c=\Psi(p, k)[Y(x, z, l, n)-g],
$$

where $p$ is the number of adult members in a household, $k$ is the number of children, and $g$ is the goods spent on kids. Let

$$
\Psi(p, k)=\frac{1}{(p+b k)^{\sigma}} .
$$

Agents draw $\gamma$ before they decide whether to accept or reject a match. Let $\gamma \in\left\{\gamma_{1}, \ldots, \gamma_{S}\right\}$, and assume that

$$
\operatorname{Pr}\left[\gamma=\gamma_{i}\right]=\Gamma\left(\gamma_{i}\right), \text { and } \operatorname{Pr}\left[\gamma^{\prime}=\gamma_{j} \mid \gamma=\gamma_{i}\right]=\Lambda\left(\gamma_{j} \mid \gamma_{i}\right)
$$

Human capital investment per child is determined by

$$
h=H\left(g, t, k_{1}, k_{2}\right)=\left(\frac{g}{k_{1}^{\psi}+k_{2}^{\psi}}\right)^{\alpha}\left(\frac{t}{k_{1}^{\psi}+k_{2}^{\psi}}\right)^{1-\alpha},
$$

recall that $g$ is goods investment in kids, and $t$ is time investment. It is likely that there is sharing of goods and time across children. We assume that sharing only occurs across children of the same age. When the $\psi$ parameter is 1 there is no sharing and when the $\psi$ parameter is 0 there is complete sharing. At the end of their childhood each child will receive a total human capital investment of $h=h_{-1}+h_{-2}$. Given this human capital investment, each female and male child will have an initial productivity draw according to

$$
\operatorname{Pr}\left[x=x_{i}\right]=\Xi\left[x=x_{i} \mid h\right] \text {, and } \operatorname{Pr}\left[z=z_{i}\right]=\Theta\left[z=z_{i} \mid h\right]
$$

In the second and third periods, the productivity levels evolve according to

$$
X\left(x_{j} \mid x_{i}, l_{-1}\right)=\operatorname{Pr}\left[x^{\prime}=x_{j} \mid x=x_{i}, l_{-1}\right]
$$


where $l_{-1}$ is the last period's labor supply. Similarly,

$$
Z\left(z_{j} \mid z_{i}, n_{-1}\right)=\operatorname{Pr}\left[z^{\prime}=z_{j} \mid z=z_{i}, n_{-1}\right]
$$

This is meant to capture the observation that if you take time out of the labor market your productivity will fall in subsequent periods.

\subsection{Decisions}

At the beginning of each period, single agents meet in a marriage market. If a couple chooses to marry, decisions within the marriage are given by the Nash solution to a fixedthreat bargaining game, where the threat points are the values of continuing life as single agents. The couple decides how many kids to have, how much to work, and how much to invest in their children.

Two-period old agents made fertility decisions in the previous period. Hence, some two-period old single women will now have two-period old kids when they look for a partner. Married or single, two-period old females will also decide whether to have more kids. There is no fertility decision for three-period old women. Some of the three-period old women may have two-period old kids that were born last period. When we refer to single men, we will only indicate their productivity levels. For women, however, we will indicate both their productivity levels and the number of two-period old kids that they have.

At the beginning of each period, all one-period old agents are single (they have just become adults). They will match with each other and decide whether or not to get married. Among two-period old agents, some are married and some are single at the beginning of a period. Married agents will decide whether to stay married or get divorced. Then, all single agents (including those who recently divorced) will match with each other. Among these matches, some will result in marriages, and some will not. Those who do not marry will wait until the next period to be matched with those who will get divorced next period or those who decided to remain single this period.

\subsubsection{Third Period}

We start from the last period of an agent's life. Since women can only have children during the first two periods of their adulthood, three-period old adults do not make fertility decisions. A three-period old woman has either no kids at home (she may have had kids in 
the first period of her life who are now adults), or kids that are two periods old (they were born last period). The utility of being single for a woman who is type- $x$ and has $k$ kids ( $k$ two-period old kids and no one-period old kids) is

$$
G_{3}(x, 0, k)=\max _{l, t, g}\left\{F\left(c, h, 0, k, 1-l-t-\chi_{f}(0, k)\right)\right\}
$$

subject to

$$
\begin{gathered}
c=\Psi(p, k)[x l-g], \\
h=H(g, t, 0, k) .
\end{gathered}
$$

Let the human capital investment decision for a three-period old single woman be given by

$$
h=H_{3}^{s}\left(g_{3}^{s}(x, k), t_{3}^{s}(x, k), 0, k\right),
$$

where $g_{3}^{s}(x, k)$ and $t_{3}^{s}(x, k)$ are solutions to $\mathrm{P}(3 \mathrm{a})$. Similarly, let

$$
B_{3}(z)=\max _{n}\{M(z n, 0,0,0,1-n)\},
$$

be the value of single life for a three-period old man.

We refer to three-period old newly-matched couples as new marriages. A threeperiod old married couple can only have children who are now two periods old. For a couple with $k$ two-period old kids and a match quality, $\gamma$, the value of being newly married, when the only outside option is to be single, is given by

$\max _{l, n, t, g}\left[F\left(c, h, 0, k, 1-l-t-\chi_{f}(0, k)\right)-G_{3}(x, 0, k)\right]\left[M\left(c, h, 0, k, 1-n-\chi_{m}(0, k)\right)-B_{3}(z)\right]$ subject to

$$
\begin{gathered}
c=\Psi(2, k)[x l+z n-g], \quad P(3 n) \\
h=H(g, t, 0, k) .
\end{gathered}
$$

Married agents reach their decisions by Nash Bargaining. Denote the human capital investment decision of a three-period old newly married couple by

$$
h=H_{3}^{n m}\left(g_{3}^{n m}(x, z, k, \gamma), t_{3}^{n m}(x, z, k, \gamma), 0, k\right) .
$$


Let $W_{3}^{n}(x, z, 0, k, \gamma)$ be the value of being newly married for a woman and $V_{3}^{n}(x, z, 0, k, \gamma)$ be the value of being newly married for a man. Let $I_{3}^{n}(x, z, 0, k, \gamma)$ be the indicator function for the marriage decision of a newly matched, three-period old couple of type $(x, z, k, \gamma)$,

$$
I_{3}^{n}(x, z, 0, k, \gamma)=\left\{\begin{array}{c}
1, W_{3}^{n}(x, z, 0, k, \gamma) \geq G_{3}(x, 0, k) \text { and } \\
V_{3}^{n}(x, z, 0, k, \gamma) \geq B_{3}(z) \\
0, \text { otherwise }
\end{array} \quad P\left(3 n^{\prime}\right)\right.
$$

Note that $I_{3}^{n}(x, z, 0, k, \gamma)$ gives the marriage decision for all three-period old new matches.

We also have three-period old already-married couples, or old marriages. A threeperiod old, already-married couple can only have children who are now two-periods old. For a couple with $k$ two-period old kids and a match quality, $\gamma$, the value of being married, when the outside option is to take a new draw from the marriage market, is given by

$$
\begin{aligned}
\max _{l, n, t, g}\left[F\left(c, h, 0, k, 1-l-t-\chi_{f}(0, k)\right)-E W_{3}^{d r}(x, k)\right] & \\
& {\left[M\left(c, h, 0, k, 1-n-\chi_{m}(0, k)\right)-E V_{3}^{d r}(z]\right] }
\end{aligned}
$$

subject to

$$
\begin{gathered}
c=\Psi(2, k)[x l+z n-g], \\
h=H(g, t, 0, k),
\end{gathered}
$$

where $E W_{3}^{d r}(x, k)$ and $E V_{3}^{d r}(z)$ are the expected values of taking a draw in the marriage market for women and men, respectively. Already married agents also reach their decisions by Nash Bargaining. The threat point here is now the expected utility of a draw from the marriage market. Denote the human capital investment decision of a three-period old, already-married couple by

$$
h=H_{3}^{o m}\left(g_{3}^{o m}(x, z, k, \gamma), t_{3}^{o m}(x, z, k, \gamma), 0, k\right) .
$$

Let $W_{3}^{o}(x, z, 0, k, \gamma)$ be the value of being already married for a female and $V_{3}^{o}(x, z, 0, k, \gamma)$ be the value of being already married for a male. The decision of a three-period old couple that considers divorce, is given by

$$
I_{3}^{o}(x, z, 0, k, \gamma)=\left\{\begin{array}{l}
1, W_{3}^{o}(x, z, 0, k, \gamma) \geq E W_{3}^{d r}(x, k) \\
\text { and } V_{3}^{o}(x, z, 0, k, \gamma) \geq E V_{3}^{d r}(z) \\
0, \text { otherwise }
\end{array}\right.
$$


The expected values of having a new draw from the marriage market are given by,

$$
\begin{gathered}
E W_{3}^{d r}(x, k)=E_{z, \gamma}\left[W_{3}^{n}(x, z, 0, k, \gamma) I_{3}^{n}(x, z, 0, k, \gamma)+G_{3}(x, 0, k)\left(1-I_{3}^{n}(x, z, 0, k, \gamma)\right)\right] \\
=\sum_{h} \sum_{m}\left[W_{3}^{n}\left(x, z_{h}, 0, k, \gamma_{m}\right) I_{3}^{n}\left(x, z_{h}, 0, k, \gamma_{m}\right)+G_{3}(x, 0, k)\left(1-I_{3}^{n}\left(x, z_{h}, 0, k, \gamma_{m}\right)\right)\right] \Omega_{3}\left(z_{h}\right) \Gamma\left(\gamma_{m}\right),
\end{gathered}
$$

and

$$
\begin{aligned}
& E V_{3}^{d r}(z)=E_{x, k, \gamma}\left[V_{3}^{n}(x, z, 0, k, \gamma) I_{3}^{n}(x, z, 0, k, \gamma)+B_{3}(z)\left(1-I_{3}^{n}(x, z, 0, k, \gamma)\right)\right] \\
& =\sum_{h} \sum_{k} \sum_{m}\left[V_{3}^{n}\left(x_{h}, z, 0, k, \gamma_{m}\right) I_{3}^{n}\left(x_{h}, z, 0, k, \gamma_{m}\right)+B_{3}(z)\left(1-I_{3}^{n}\left(x_{h}, z, 0, k, \gamma_{m}\right)\right)\right] \Phi_{3}\left(x_{h}, k\right) \Gamma\left(\gamma_{m}\right),
\end{aligned}
$$

where $\Phi_{3}(x, k)$ is the probability of meeting a three-period old single woman of type- $x$, with $k$ two-period old kids, in the third period marriage market, and $\Omega_{3}(z)$ is the probability of meeting a three-period old single man of type- $z$, in the third period marriage market.

\subsubsection{Second Period}

The second period decision process differs from the third period decision process in that there is now a fertility decision. Single women and married couples choose the number of new children to have, along with how much to work and how much to invest in all children in the household. A two-period old woman can have kids that are two periods old (they will become adults and leave the house next period). She can also choose to have more kids. The value of being a two-period old single woman of type- $x$, who has $k$ one-period and $k_{2}$ two-period old kids is

$G_{2}\left(x, k, k_{2}\right)=\max _{l, t, g}\left\{F\left(c, h, k, k_{2}, 1-l-t-\chi_{f}\left(k, k_{2}\right)\right)+\sum_{i} E W_{3}^{d r}\left(x_{i}, k\right) X\left(x_{i} \mid x, l\right)\right\}$

subject to

$$
\begin{gathered}
c=\Psi\left(1, k+k_{2}\right)[x l-g], \\
h=H\left(g, t, k, k_{2}\right) .
\end{gathered}
$$

Let $G_{2}\left(x, k_{2}\right)$ be the value of being a two-period old single woman of type- $\left(x, k_{2}\right)$. It is given by

$$
G_{2}\left(x, k_{2}\right)=\max _{k}\left\{G_{2}\left(x, k, k_{2}\right)\right\}
$$

Let

$$
K_{2}^{s}\left(x, k_{2}\right)=\arg \max _{k}\left\{G_{2}\left(x, k, k_{2}\right)\right\}
$$


represent the fertility decision of a two-period old single woman. The human capital investment by a two-period old single woman is then given by

$$
h=H_{2}^{s}\left(g_{2}^{s}\left(x, k_{2}\right), t_{2}^{s}\left(x, k_{2}\right), K_{2}^{s}\left(x, k_{2}\right), k_{2}\right) .
$$

We can define $B_{2}(z)$ in a similar way

$$
B_{2}(z)=\max _{n}\left\{M(z n, 0,0,0,1-n)+\sum_{h} E V_{3}^{d r}\left(z_{h}\right) Z\left(z_{h} \mid z, n\right)\right\}
$$

The value of being newly married for a two-period old woman of type- $x$, a two-period old man of type- $z$, with $k_{2}$ two-period old kids, and a match quality, $\gamma$, is given by

$$
\begin{gathered}
\max _{l, t, n, g, k}\left[F\left(c, h, k, k_{2}, 1-l-t-\chi_{f}\left(k, k_{2}\right)\right)+\sum_{i} \sum_{h} \sum_{m} \max \left\{W_{3}^{o}\left(x_{i}, z_{h}, 0, k, \gamma_{m}\right) I_{3}^{o}\left(x_{i}, z_{h}, 0, k, \gamma_{m}\right),\right.\right. \\
\left.\left.E W_{3}^{d r}\left(x_{i}, k\right)\right\} X\left(x_{i} \mid x, l\right) Z\left(z_{h} \mid z, n\right) \Lambda\left(\gamma_{m} \mid \gamma\right)-G_{2}\left(x, k_{2}\right)\right] \quad P(2 n) \\
{\left[M\left(c, h, k, k_{2}, 1-n-\chi_{m}\left(k, k_{2}\right)\right)+\sum_{i} \sum_{h} \sum_{m} \max \left\{V_{3}^{o}\left(x_{i}, z_{h}, 0, k, \gamma_{m}\right) I_{3}^{o}\left(x_{i}, z_{h}, 0, k, \gamma_{m}\right),\right.\right.} \\
\left.\left.E V_{3}^{d r}\left(z_{h}\right)\right\} X\left(x_{i} \mid x, l\right) Z\left(z_{h} \mid z, n\right) \Lambda\left(\gamma_{m} \mid \gamma\right)-B_{2}(z)\right]
\end{gathered}
$$

subject to

$$
\begin{gathered}
c=\Psi\left(2, k+k_{2}\right)[x l+z n-g], \\
h=H\left(g, t, k, k_{2}\right) .
\end{gathered}
$$

The utility of being married today also includes the possible gains from remaining married to your spouse next period, or getting divorced and taking a draw from next period's marriage market. Since this is a new marriage, the threat point only includes the possibility of remaining single in the second period. Let

$$
h=H_{2}^{n m}\left(g_{2}^{n m}\left(z, x, k_{2}, \gamma\right), t_{2}^{n m}\left(z, x, k_{2}, \gamma\right), K_{2}^{n m}\left(x, z, k_{2}, \gamma\right), k_{2}\right)
$$

be the level of human capital investment by a two-period old, newly-married couple with $k_{2}$ two-period old kids and $K_{2}^{n m}\left(x, z, k_{2}, \gamma\right)$ one-period old kids.

Let the utility of being in a new marriage be $W_{2}^{n}\left(x, z, k_{2}, \gamma\right)$ for a female and $V_{2}^{n}\left(x, z, k_{2}, \gamma\right)$ for a male, and the associated indicator function be given by

$$
I_{2}^{n}\left(x, z, k_{2}, \gamma\right)=\left\{\begin{array}{cc}
1, & W_{2}^{n}\left(x, z, k_{2}, \gamma\right) \geq G_{2}\left(x, k_{2}\right) \text { and } \\
\quad V_{2}^{n}\left(x, z, k_{2}, \gamma\right) \geq B_{2}(z) \\
0, \text { otherwise }
\end{array} \quad P\left(2 n^{\prime}\right)\right.
$$


For already-married couples, the value of being married for a two-period old female of type- $x$, a two-period old male of type- $z$, with $k_{2}$ two-period old kids and a match quality, $\gamma$, is given by

$$
\begin{gathered}
\max _{k, l, t, n, g}\left[F\left(c, h, k, k_{2}, 1-l-t-\chi_{f}\left(k, k_{2}\right)\right)+\sum_{i} \sum_{h} \sum_{m} \max \left\{W_{3}^{o}\left(x_{i}, z_{h}, 0, k, \gamma_{m}\right)\right.\right. \\
\left.\left.I_{3}^{o}\left(x_{i}, z_{h}, 0, k, \gamma_{m}\right), E W_{3}^{d r}\left(x_{i}\right)\right\} X\left(x_{i} \mid x, l\right) Z\left(z_{h} \mid z, n\right) \Lambda\left(\gamma_{m} \mid \gamma\right)-E W_{2}^{d r}\left(x, k_{2}\right)\right] \\
{\left[M\left(c, h, k, k_{2}, 1-n-\chi_{m}\left(k, k_{2}\right)\right)+\sum_{i} \sum_{h} \sum_{m} \max \left\{V_{3}^{o}\left(x_{i}, z_{h}, 0, k, \gamma_{m}\right) I_{3}^{o}\left(x_{i}, z_{h}, 0, k, \gamma_{m}\right),\right.\right.} \\
\left.\left.E V_{3}^{d r}\left(z_{h}\right)\right\} X\left(x_{i} \mid x, l\right) Z\left(z_{h} \mid z, n\right) \Lambda\left(\gamma_{m} \mid \gamma\right)-E V_{2}^{d r}(z)\right],
\end{gathered}
$$

subject to

$$
\begin{gathered}
c=\Psi\left(2, k+k_{2}\right)[x l+z n-g], \\
h=H\left(g, t, k, k_{2}\right),
\end{gathered}
$$

where, the expected values of taking a draw in the second period marriage market for men and women are given by $E V_{2}^{d r}(z)$ and $E W_{2}^{d r}\left(x, k_{2}\right)$, respectively.

Let $h=H_{2}^{o m}\left(g_{2}^{o m}\left(z, x, k_{2}, \gamma\right), t_{2}^{o m}\left(z, x, k_{2}, \gamma\right), K_{2}^{o m}\left(x, z, k_{2}, \gamma\right), k_{2}\right)$, be the level of human capital investment by a two-period old, already-married couple with $k_{2}$ two-period old kids and $K_{2}^{o m}\left(x, z, k_{2}, \gamma\right)$ one-period old kids. Let the utility of being in an old marriage be $W_{2}^{o}\left(x, z, k_{2}, \gamma_{r}\right)$ for a female and $V_{2}^{o}\left(x, z, k_{2}, \gamma_{r}\right)$ for a male. For a two-period old couple that considers divorce, we have the following indicator function,

$$
I_{2}^{o}\left(x, z, k_{2}, \gamma\right)=\left\{\begin{array}{l}
1, W_{2}^{o}\left(x, z, k_{2}, \gamma\right) \geq E W_{2}^{d r}\left(x, k_{2}\right) \text { and } \\
V_{2}^{o}\left(x, z, k_{2}, \gamma\right) \geq E V_{2}^{d r}(z) \\
0, \text { otherwise }
\end{array}\right.
$$

where

$$
\begin{gathered}
E W_{2}^{d r}\left(x, k_{2}\right)=E_{z, \gamma}\left[W_{2}^{n}\left(x, z, k_{2}, \gamma\right) I_{2}^{n}\left(x, z, k_{2}, \gamma\right)+G_{2}\left(x, k_{2}\right)\left(1-I_{2}^{n}\left(x, z, k_{2}, \gamma\right)\right)\right]= \\
\sum_{h} \sum_{m}\left\{W_{2}^{n}\left(x, z_{h}, k_{2}, \gamma_{m}\right) I_{2}^{n}\left(x, z_{h}, k_{2}, \gamma_{m}\right)+\right. \\
\left.G_{2}\left(x, k_{2}\right)\left(1-I_{2}^{n}\left(x, z_{h}, k_{2}, \gamma_{m}\right)\right)\right\} \Omega_{2}\left(z_{h}\right) \Gamma\left(\gamma_{m}\right),
\end{gathered}
$$

and

$$
\begin{gathered}
E V_{2}^{d r}(z)=E_{x, k_{2}, \gamma}\left[V_{2}^{n}\left(x, z, k_{2}, \gamma\right) I_{2}^{n}\left(x, z, k_{2}, \gamma\right)+B_{2}(z)\left(1-I_{2}^{n}\left(x, z, k_{2}, \gamma\right)\right)\right]= \\
\sum_{h} \sum_{k_{2}} \sum_{m}\left\{V_{2}^{n}\left(x_{h}, z, k_{2}, \gamma_{m}\right) I_{2}^{n}\left(x_{h}, z, k_{2}, \gamma_{m}\right)+\right. \\
\left.B_{2}(z)\left(1-I_{2}^{n}\left(x_{h}, z, k_{2}, \gamma_{m}\right)\right)\right\} \Phi_{2}\left(x_{h}, k_{2}\right) \Gamma\left(\gamma_{m}\right) .
\end{gathered}
$$




\subsubsection{First Period}

In the first period, the decision process is simplified because there are no already-married couples at the beginning of the first period. The value of being a one-period old single woman of type- $x$ with $k$ one-period old kids, is given by

$G_{1}(x, k, 0)=\max _{l, t, g}\left\{F\left(c, h, k, 0,1-l-t-\chi_{f}(k, 0)\right)+\sum_{i} E W_{2}^{d r}\left(x_{i}, k\right) X\left(x_{i} \mid x, l\right)\right\} . \quad P(1 a)$

The value of being a single, one-period old woman of type- $x$ is given by

$$
G_{1}(x)=\max _{k}\left\{G_{1}(x, k, 0)\right\}
$$

Let $K_{1}^{s}(x)$ be the optimal child choice of the first period single woman with productivity $x$. Let a one-period old single woman make the following human capital investment in her children:

$$
h=H_{1}^{s}\left(g_{1}^{s}(x), t_{1}^{s}(x), K_{1}^{s}(x), 0\right) .
$$

We can similarly define $B_{1}(z)$ for one-period old single men, and $W_{1}^{n}(x, z, \gamma)$ and $V_{1}^{n}(x, z, \gamma)$ for one-period old, newly-married couples, and their corresponding fertility decisions, $K_{1}^{n m}(x, z, \gamma)$. Note that all marriages in period one are new marriages. The marriage decisions for the matches between one-period old single women and one-period old single men are given by

$$
I_{1}^{n}(x, z, \gamma)=\left\{\begin{array}{c}
1, W_{1}^{n}(x, z, \gamma) \geq G_{1}(x) \text { and } \\
V_{1}^{n}(x, z, \gamma) \geq B_{1}(z) \\
0, \text { otherwise }
\end{array} \quad P\left(1 n^{\prime}\right)\right.
$$

\subsection{Discussion}

We would prefer to have a more realistic life-cycle, comprising say one period for each year of the lifespan. However the decision-theoretic problem of optimal timing of fertility becomes enormously difficult as the number of periods increases, to say nothing of the problem of computing and updating equilibrium distributions of households across ages of parents and children. While there does exist recent work on fertility timing with many periods (such as Hotz and Miller (1988), Eckstein and Wolpin (1989), and Heckman and Walker (1990)), such models abstract from computation of the equilibrium. On the other hand, work on the equilibrium side either abstracts from timing altogether or makes extreme simplifications regarding family decisions. Thus Regalia and Rios-Rull (1999) eliminate 
age as a state variable, and hence the timing decision, altogether by assuming that aging is stochastic, whereas Conesa (1999) abstracts from marriage market considerations. One of the main hypotheses of this paper is that the labor market status of women affects both their marriage decisions, and their bargaining position within marriage, hence to understand the interaction between fertility decisions and the labor market requires a model of marriage that reflects these two effects. In our model therefore, a compressed life-cycle is an inevitable simplification resulting from our emphasis on these issues of marriage dynamics.

Our model also abstracts from several public policies, such as parental leave, that can potentially have a large impact on the timing of births. The study of these issues requires a more detailed analysis of the labor market, which is kept intentionally simple in our framework. Erosa, Fuster, and Restuccia (2001) consider such polices using a model where the matching process between workers and firms is modelled more explicitly.

\section{Equilibrium}

A stationary equilibrium is a collection of value functions, household decision rules, marital decision rules and matching probabilities such that

Definition 1. A stationary matching equilibrium can be represented by a set of child quantity and quality allocation rules, $K_{1}^{n m}(x, z, \gamma), K_{2}^{n m}(x, z, k, \gamma), K_{2}^{o m}(x, z, k, \gamma), K_{1}^{s}(x)$, $K_{2}^{s}(x, k), H_{3}^{n m}\left(g_{3}^{n m}, t_{3}^{n m}, 0, k\right), H_{3}^{o m}\left(g_{3}^{o m}, t_{3}^{o m}, 0, k\right), H_{3}^{s}\left(g_{3}^{s}, t_{3}^{s}, 0, k\right), H_{2}^{n m}\left(g_{2}^{n m}, t_{2}^{n m}, K_{2}^{n m}, k\right)$, $H_{2}^{o m}\left(g_{2}^{o m}, t_{2}^{o m}, K_{2}^{o m}, k\right), H_{2}^{s}\left(g_{2}^{s}, t_{2}^{s}, K_{2}^{s}, k\right), H_{1}^{n m}\left(g_{1}^{n m}, t_{1}^{n m}, K_{1}^{n m}, 0\right)$, and $H_{1}^{s}\left(g_{1}^{s}, t_{1}^{s}, K^{s}, 0\right), a$ set of accept/reject decision rules, $I_{1}^{n}(x, z, \gamma), I_{2}^{n}(x, z, k, \gamma), I_{3}^{n}(x, z, 0, k, \gamma), I_{2}^{o}(x, z, k, \gamma)$, $I_{3}^{o}(x, z, 0, k, \gamma)$, and a set of matching probabilities, $\Phi_{1}(x), \Phi_{2}(x, k), \Phi_{3}(x, k), \Omega_{1}(z), \Omega_{2}(z)$, and $\Omega_{3}(z)$ such that:

1. The household decision rules are optimal taking as given the marital decision rules and the matching probabilities, i.e. they solve $P(3 a), P(3 b), P(3 n), P(30), P(2 a)$, $P(2 b), P(2 n), P(2 o)$, and $P(1 a)$ defined above (as well as corresponding problems for one-year-old single men and one year old newly married couples that are not explicitly defined).

2. The marital decision rules for a given sex are optimal, taking as given the marital decision rules of the other sex, the household decision rules and the matching probabilities, i.e. they solve $P\left(3 n^{\prime}\right), P\left(3 o^{\prime}\right), P\left(2 n^{\prime}\right), P\left(2 o^{\prime}\right)$ and $P\left(1 n^{\prime}\right)$ defined above. 
3. The matching probabilities, $\Phi_{1}(x), \Phi_{2}(x, k), \Phi_{3}(x, k), \Omega_{1}(z), \Omega_{2}(z)$, and $\Omega_{3}(z)$ are the fixed points of the mappings implied by the marital and household decision rules.

\subsection{Computation}

Given the measures of each type in the marriage market, in each period, $\Omega_{1}(z), \Phi_{1}(x), \Omega_{2}(z)$, $\Phi_{2}(x, k), \Omega_{3}(z)$, and $\Phi_{3}(x, k)$, we solve the model working backwards from period three. For married couples, this requires finding the Nash solution to the bargaining game where the threat points are the values of life as singles. It is well-known that the Nash solution to the bargaining game maximizes the product of the net gains of the participants. Instead of solving the couple's bargaining problem directly, we maximize the weighted sums of the spouse's utility from marriage, and then choose the weights so that the solution maximizes the product of the gains from marriage. Since the Nash solution is a selection from the set of Pareto-optimal allocations, such a weight must exist if the problem is well-defined. Furthermore, provided that concavity of the product is satisfied, which is the case in our model, then the weight that equates the two problems is given by a simple first-order condition. $^{4}$

Clearly, successful computation depends on the concavity of the objective functions of the weighted Pareto problems. In the first and the second periods these objective functions contain future continuation utility, as future productivity depends on current labor. The concavity of the objective function with respect to labor is maintained through appropriate restrictions on the functional forms that link future productivity and current labor. ${ }^{5}$ The reason we need restrictions on the continuation values is the following: when a married couple decides how much each one should work, even though each is better off by working more and accumulating more human capital, it is not clear that they are always better off if their partner works more. If the partner works more and accumulates more human capital, he or she has more of an incentive to leave the current partner and look for a better one. Hence, from the perspective of men and women, the continuation values are not simple functions of current labor supply decisions. Once we have computed the decisions, we then update $\Omega$ and $\Phi$. The solution is a fixed point of the $\Omega$ and $\Phi$ distributions.

\footnotetext{
${ }^{4}$ For more details on the computational method, see the Appendix A.

${ }^{5}$ For the proof of concavity, given our functional forms, see Appendix B.
} 


\section{Calibration}

We think of each model period as 10 years, and the 3 periods of the model as representing ages 20-29, 30-39, and 40-49. Obviously, it is not a straightforward job to find statistics with which to calibrate a model when each period is 10 years long and each adult lives for 30 years. One possibility is to focus on a 10 years-interval-birth cohort and to tune the model economy to match their lifetime marital and labor market experiences. The other possibility is to focus on statistics from a particular year or years, under the assumption that statistics generated by a cross section of people in that particular year or years correspond to our benchmark economy. Although the first route might be more desirable, in selecting our targets for calibration we will use both types of statistics. Our benchmark economy is parameterized to generate statistics that are roughly in line with statistics on marital status, timing of births, income inequality and labor supply statistics from the early $1970{ }^{6}{ }^{6}$

Decisions regarding the functional forms and parameters of a large scale general equilibrium model such as this can be difficult to make and yet crucial to model outcomes. In some cases, there are estimates in the literature that we use to guide our parameter choice. In other cases, we choose parameters in our model so that the steady-state outcomes of the model are consistent with the relevant statistics from the PSID, CPS and National Center for Health Statistics data sets. Still there are functional forms and parameters for which we have little information to guide us. In the following subsection we discuss those parameters that we take directly from data; the remaining parameters are chosen to match as closely as possible the statistics on fertility, marriage and labor supply that we reported in the previous section.

\subsection{Parameters chosen to match data}

- Productivity levels:

$$
x \in\left\{x_{1}, \ldots, x_{7}\right\}, \quad z \in\left\{z_{1}, \ldots, z_{7}\right\} .
$$

${ }^{6}$ This is mainly motivated by significant changes in marital status (see e.g. Regalia and Rios-Rull (1999)) and in labor supply behavior (see e.g. Olivetti (2001)) that took place between early 1970s and the present day. While we focus on early 1970s as our benchmark, our main interest is to shed light onto the changes that took place afterwards. 
We use the mean and standard deviation of log-wages for men and women to create the grids of productivity levels:

$$
\begin{gathered}
x_{1}=m l x-2 s d l x, \quad x_{2}=x_{1}+\frac{4 s d l x}{N-1}, \quad \ldots, \quad x_{7}=m l x+2 s d l x, \\
z_{1}=m l z-2 s d l z, \quad z_{2}=z_{1}+\frac{4 s d l z}{N-1}, \quad \ldots, \quad z_{7}=m l z+2 s d l z .
\end{gathered}
$$

The lowest value is two standard deviations below the mean, and the highest value is two standard deviations above the mean. We use $m l z=2.3, s d l z=.55, m l x=2.0$, $s d l x=.55$, moments based on the empirical wage distributions. The mean and standard deviations of these grid points are taken from 1988 PSID wages (annual earnings divided by annual hours) for full-time, nonfarm wage and salary employees aged 18-65. We focus on a large age group to capture the range of wages one can have over his/her lifetime.

- Scale in household consumption:

$$
\Psi(p, k)=\frac{1}{(p+b k)^{\sigma}} .
$$

Here the parameter $b$ represents how much kids consume relative to adults. The parameter $\sigma$ measures how much is gained by consolidating several adult-equivalents into a single household. Cutler and Katz (1992) report ranges of estimates for these parameters. We use $b=.5$ and $\sigma=.5$, which are in the middle of these ranges.

- Fixed cost of children:

$$
\chi_{f}\left(k_{1}, k_{2}\right)=\chi_{f}^{1} k_{1}+\chi_{f}^{2} k_{2}, \quad \chi_{m}\left(k_{1}, k_{2}\right)=\chi_{m}^{1} k_{1}+\chi_{m}^{2} k_{2} .
$$

There are some estimates of these parameters for women. Hotz and Miller (1988) report that a newborn requires 660 hours of parental time per year. ${ }^{7}$ This requirement declines geometrically at a rate of $12 \%$ per year. If people have 16 hours of nonsleeping time, in its first year a newborn takes up 11.3 percent of a woman's potential work and leisure time. Using the fact that a period is ten years and that there is $12 \%$ depreciation, we get $\chi_{f}^{1}=.0736$ and $\chi_{f}^{2}=.0257$. The values for men should be less than those for women, but there are no easily available numbers.

\footnotetext{
${ }^{7}$ One can imagine that over time improvements in child care technology will allow women to spend less time with kids and more time in the labor market.
} 


\section{- Discount factor}

Since a model period is ten years, if we assume that the interest rate is $4 \%$, then $\beta=.676$.

\subsection{Parameters chosen to match model to data}

The remaining parameters are selected to match statistics on marital status, timing of births, labor supply, income inequality, and investment in children. Since most of these statistics are affected by several parameters at the same time, it is hard to point out particular targets for the remaining parameters. We list the parameters and the statistics that they have most affect on.

- Marriage match quality:

The quality levels $\left(\left\{\gamma_{1}=0.8, \gamma_{2}=1.8\right\}\right.$ for the first two periods and $\left\{\gamma_{1}=0.5, \gamma_{2}=1.2\right\}$ for the last period) and unconditional and conditional probabilities $\left(\Gamma\left(\gamma_{1}\right)=0.4\right.$, $\Gamma\left(\gamma_{2}\right)=0.6, \Lambda\left(\gamma_{1} \mid \gamma_{1}\right)=0.4$ and $\left.\Lambda\left(\gamma_{2} \mid \gamma_{2}\right)=0.6\right)$ are chosen so that the model quantities match the fractions of single, married and divorced people in the data. ${ }^{8}$

- Human capital production for children:

Although an important part of the model, there is little help from the available evidence to guide our selection of the functional forms and parameters that govern the human capital production for children. ${ }^{9}$ We pick the following

$$
H\left(g, t, k_{1}, k_{2}\right)=\left(\frac{g}{k_{1}^{0.3}+k_{2}^{0.3}}\right)^{0.38}\left(\frac{t}{k_{1}^{0.3}+k_{2}^{0.3}}\right)^{1-0.38}
$$

Here the parameter $\psi=.3$, represents how much sharing there is across siblings in the same age category. If $\psi=1$ there is no sharing of time or goods, and if $\psi=0$ there is complete sharing of time and goods. While the main targets for these parameters

${ }^{8}$ Note that although utility from marriage is also affected by other parameters, the match quality in a given period has no affect on decisions within a marriage and only affects the decision to get married.

${ }^{9}$ Aiyagari, Greenwood, and Guner (2000) and Greenwood, Guner, and Knowles (2000) uses human capital production functions that are similar to the one used here. Restuccia and Urrutia (2001) use a human capital function where the only input is goods spent on children and the spending is subject to decreasing returns. While these papers attempt to analyze different question, they all are able generate a high degree of persistence across generations. 
are the amount of goods and time invested in children, they obviously affect other decisions (such as fertility).

- Parameters that map childhood investment into productivity:

$$
\operatorname{Pr}\left[x=x_{i}\right]=\Xi\left[x=x_{i} \mid h\right], \quad \operatorname{Pr}\left[z=z_{i}\right]=\Theta\left[z=z_{i} \mid h\right]
$$

We use a log-linear approximation given by

$$
\log (x)=\log \left(10.1 h^{0.5}\right)
$$

Note that $a=10.1$ is simply a scaling parameter. The curvature parameter, $d=.5$, plays a larger role. If $d=1$ the dispersion between high and low $h$ kids is large. Since we use log-linear approximation to map human capital investment into the 7 productivity types, we also need to select a standard deviation for our approximation (which is set to be 0.45 ). These parameters are chosen so that the distribution of first period adult types, $\Phi_{1}$ and $\Omega_{1}$, look log-normal, that is the initial distribution of kids has the same mean and standard deviation that are used for creating the grid of productivity levels.

\section{- Utility parameters:}

We still have four utility parameters and the fixed time cost for males to pick. These are selected to match the timing of fertility, fertility level, and labor supply levels. Again it is easy to see that all of these targets are also affected by other parameters, although the main effect on fertility and labor supply levels are determined by the utility parameters:

$$
\begin{aligned}
& F\left(c, h, k_{1}, k_{2}, 1-l-t-\chi_{f}\left(k_{1}, k_{2}\right)\right)=\frac{c^{0.5}}{0.5}+0.38 \frac{k^{0.35}}{0.35} \frac{h^{0.3}}{0.3}+3.6 \frac{\left(1-l-t-\chi_{f}\left(k_{1}, k_{2}\right)\right)^{0.05}}{0.05}-\gamma, \\
& M\left(c, h, k_{1}, k_{2}, 1-n-\chi_{m}\left(k_{1}, k_{2}\right)\right)=\frac{c^{0.5}}{0.5}+0.38 \frac{k^{0.35}}{0.35} \frac{h^{0.3}}{0.3}+3.6 \frac{\left(1-n-\chi_{m}\left(k_{1}, k_{2}\right)\right)^{0.05}}{0.05}-\gamma,
\end{aligned}
$$

where $\chi_{m}^{1}=0.0478$, and $\chi_{m}^{2}=0.0167$.

- Return to working:

$$
X\left(x_{j} \mid x_{i}, l_{-1}\right)=\operatorname{Pr}\left[x^{\prime}=x_{j} \mid x=x_{i}, l_{-1}\right] .
$$


Moffitt (1984) finds an additional year of work experience raises the wage by a little more than 4\%. Blau and Kahn (1997) find that an additional year of full time experience increases in log-female wages by .0289 and male wages by .0458 in 1988 . More recently, Olivetti (2000) estimates the return to experience for men and women, and shows that there has been a significant rise in the returns to experience for females. Since we have a finite number of productivity types in the model, we would like to model the returns to experience as a function that maps current productivity levels and current labor supply decisions into the next period's productivity levels. The following matrix shows our specification for this process. In the matrix each row represents the current value of productivity and each entry represents the probability of reaching a particular productivity next period as a function of labor supply $n$.

\begin{tabular}{|c|c|c|c|c|c|c|}
\hline $1-n$ & $.8 n$ & $.2 n$ & 0 & 0 & 0 & 0 \\
\hline $1-n^{0.8}$ & $.4 n^{0.8}$ & $.3 n^{0.8}$ & $.2 n^{0.8}$ & $.1 n^{0.8}$ & 0 & 0 \\
\hline $.3\left(1-n^{0.8}\right)$ & $.7\left(1-n^{0.8}\right)$ & $.3 n^{0.8}$ & $.3 n^{0.8}$ & $.2 n^{0.8}$ & $.1 n^{0.8}$ & $.1 n^{0.8}$ \\
\hline 0 & $.3\left(1-n^{0.8}\right)$ & $.7\left(1-n^{0.8}\right)$ & $.3 n^{0.8}$ & $.3 n^{0.8}$ & $.3 n^{0.8}$ & $.1 n^{0.8}$ \\
\hline 0 & 0 & $.3\left(1-n^{0.8}\right)$ & $.7\left(1-n^{0.8}\right)$ & $.4 n^{0.8}$ & $.3 n^{0.8}$ & $.3 n^{0.8}$ \\
\hline 0 & 0 & 0 & $.1\left(1-n^{0.5}\right)$ & $.2\left(1-n^{0.5}\right)$ & $.7\left(1-n^{0.5}\right)$ & $n^{0.5}$ \\
\hline 0 & 0 & 0 & 0 & 0 & $1-n^{0.3}$ & $n^{0.3}$ \\
\hline
\end{tabular}

In our benchmark economy, males face the returns to experience characterized by this matrix, whereas females face a fixed wage rate for all three periods of their lifetime (i.e. their wages are not affected by how much they work). These parameters are chosen to generate wage growth rates over the life cycle that are similar to what we observe in the data.

\section{The Benchmark Economy}

How does our benchmark economy match up with the data? Table 6 shows several statistics from our benchmark economy and compares them with the relevant empirical statistics. While there are many statistics one could focus on to judge the performance of such a model, we restrict our attention to those that reflect most directly the interaction between marriage and labor markets: timing of births, marital status of the population, income inequality between single and married, and the life-cycle pattern of labor supply. 
The model performs well in these dimensions. About $35 \%$ of kids are born in the second period compared to $36 \%$ in the data. The data on timing of births is from Table 2 and represent the fertility experience of the 1950-59 birth cohort. About $68 \%$ of the population is married compared to $73 \%$ in the data (for females ages 20-49), while the total fertility rate in the model is slightly higher than in the data. The model matches well with the ratio of labor earnings in female-headed households to those of married couples for younger age groups. The data on labor earnings come from Table $3 \mathrm{~b}$ and represent the evidence from the 1948-1957 birth cohort, and the ratio of labor earnings for singles and divorced to those for married. The model results for the 30-39 age group imply that female headed households do worse than in the data, an issue we will return to briefly. The labor supply numbers for single men and women line up well with the data, although married men in the model work more than the ones in the data and married women work much less. The data on labor supply are again those for the birth cohort 1948-57. The growth rate of the wages for married males that comes from the model is close to what we observe in the data (43\% vs. $39 \%)$. For married females, we imposed a zero growth rate in order to make as clear as possible the impact of raising the returns to experience for women. Finally, the fraction of income spent on children is consistent with the evidence from Olson (1983), who finds, using Consumer Expenditure Survey, that the total cost of raising two children from ages 0 to age 20 constitutes about $14 \%$ of family income. ${ }^{10}$

Table 7 and 8 provide a more detailed analysis of the level and the timing of fertility. The model produces the result that more productive women have fewer children, whether they are married or single. Table 7 reports total number of kids, number of kids born in the second model period and the number of kids born the first model period by the marital status and the productivity level of mothers. The marital status is for the second model period. Hence, single mothers are those who have never been married or those who experienced a divorce but did not get remarried. New marriages are those formed in the second period, while old marriages are the intact marriages from the first period. The productivity levels are the seven productivity levels used in the calibration (with $x_{4}$ being equal to the mean of log wages for 1988). In Table 7 the lowest productivity single woman has 3.79 children in her life, while the highest productivity single woman only has 1 child.

\footnotetext{
${ }^{10}$ This number is for male children and excludes the cost of housing, food and college. Since we already introduce a congestion effect in household consumption, we use costs net of housing and food.
} 
For women in old marriages these numbers are not as extreme, 2.36 and 1.88, respectively for two-period married women. The level of fertility is also declining in father's productivity levels in new and old marriages.

Table 8 gives the fraction of kids born in the second model period. Singles delay their childbearing more, i.e. a larger fraction of their kids born in the second period, than those who are married in both periods or those who are newly married. Highly productive two-period married women tend to delay their childbearing more than less productive twoperiod married women. The highest-productivity two-period married woman does $44 \%$ of her childbearing in her second period, while the least productive two-period married woman does $12 \%$ of her childbearing in the second period. Interestingly, however, this statistic is relatively constant for single women. Single women tend to have between $40 \%$ and $50 \%$ of their children in the second period regardless of their productivity level. When we consider timing as a function of the husband's productivity, we see that women married to low productivity men tend to have more of their children later (about $40 \%$ in the second period for old marriages) than women married to high productivity men (about 20\% in the second period for old marriages). However, as we noted above women married to high productivity men have fewer children over the course of their life.

How can we interpret these results? The fact that single women postpone their childbearing more than married women is a result of the fact that having children alone is a costly decision for women. Women who are single in the first period tend to wait for the second period marriage market. Once the second period marriage market is cleared, however, they have their children. The same is also true for marriages that are more likely to end up in divorce in the first period. Those marriage results in fewer kids in the first period than the ones that are more likely to remain intact. Hence there is a return to delay from the marriage market. The same force can also explain why high productivity women delay their childbearing more than low productivity women. While in an environment with returns to experience one can expect higher productivity women to postpone their childbearing decisions more than low productivity women, in our benchmark economy there is no learning by doing for women and they face a flat age-earnings profile. The returns from the marriage market, however, are not the same for high and low productivity women. Low productivity women have much less of a chance of marrying a high type in the future marriage market and hence less incentive to wait for a better match in order to have kids. 
This effect is much stronger for high types. Similarly, high type women are more likely to dump their low productivity partners from the first period and look for a more suitable mate.

Next we turn to the role of timing of births in the equilibrium income distribution. In the benchmark economy, children that are born in the second period receive about $11 \%$ more human capital investment than those born in the first period. One reason is the growth in men's productivity. There is also, however, the fact that higher productivity women tend to delay marriage. The marriage market and human capital investment in children interact through the mothers' decisions about when to have children. The timing of fertility is not the only link between marriage market and human capital investment in children. In the benchmark economy it is a big disadvantage to have a single mother. Children with single mothers receive on average about a third of the human capital investment received by those with married mothers. Any change that affects both the fraction of kids born in the second period and the fraction of kids living with single mothers can have offsetting effects on human capital investment in kids.

As a realistic model economy, the benchmark has two basic failings. First, the single women in the model tend to have too low a productivity relative to married women. One implication is that the young have too many children; in the current benchmark, all single women have a child when young. ${ }^{11}$ The model also fails to produce positive assortative mating. ${ }^{12}$ In this model, high productivity men, in return for child care services, are willing to marry low productivity women and this precludes positive assortative mating even in the absence of frictions in the marriage market. This is because women's productivity determines both how much she will work and how much time she will spend with kids. As long as women's productivity is low enough so that she does not work in the market, men prefer low productivity women to high productivity women. Once women begin to supply

\footnotetext{
${ }^{11}$ Another implication of this is that the productivity of the singles pool deteroriates with age, as the more productive get married, and the less productive married women re-enter via divorce, resulting in negative labor supply growth for single women, compared to zero in the data. This is largely a composition effect, due to the more productive singles getting married in the second period.

${ }^{12}$ See Fernandez and Rogerson (2001) for an analysis of long-run effects of increasing assortative mating on inequality. Chade and Ventura (2001) use an infinitely-live agents model of marriage formation and dissolution to analyze the effects of marriage tax. Their model is able to generate correlation between spouses' earnings similar to the data.
} 
positive labor to the market, men's preferences are monotone in women's type. ${ }^{13}$

\subsection{Changes in the Return to Experience}

Our first experiment is to change the returns to experience for females, which was set to zero in the benchmark model. In particular, we assume that now females face the same labor-experience and wage-growth schedule as men. The change in the learning by doing that we introduce is also consistent with other evidence, such as Olivetti (2001) and Blau and Khan (1997) who indicate the returns to experience has grown much faster for women than for men since the 1970s. This is especially consistent with the evidence provided by Olivetti (2001) indicating that age-earnings profiles for men and women began to have similar shapes in 1990s.

The results of this experiment, labelled experiment 1, are shown in Table 9. The change in the returns to experience for women has a large effect on the timing of births. Now about $44 \%$ of kids are born when their mother is older than 30 years, instead of the $36 \%$ in the benchmark case. Since we used the 1950-59 birth cohort to calibrate the timing of births, it makes sense to question if the shift in the model resembles what we see in the data for later cohorts. As the data in Table 2 indicate, for the birth cohort of 1960-67, about $41 \%$ of the births occurred to women older than 30 years. Although we get a larger shift in the model, the shift is of the same order of magnitude as that observed in the U.S. data.

Aggregate marital statistics are not affected by this change. The aggregate fraction of married people, however, does not tell the whole story. In the benchmark economy about $24 \%$ of women do not get married in the first period. This number jumps to $34 \%$ when we introduce returns to experience for women. What is happening is that more women choose to remain single and accumulate human capital in the first period (i.e. they refuse to marry men with low productivity). This results in fewer marriages in the first period and more marriages later on.

The labor supply numbers for women are also higher. This is not surprising as women work more to take advantage of returns to experience. Note that as more women

\footnotetext{
${ }^{13}$ Becker (1973) states that efficiency implies negative assortment when the spouse's traits are substitutes in the production of household utility, as is the case for productivity in our model. See Shimer and Smith (2000) for an extension of this result to marriage with matching frictions.
} 
work and choose to remain single in the first period, the relationship between labor supply and age also more closely resembles what we observe in the data. Finally, this change results in a more equal income distribution. Now female-headed households' labor income is about $40 \%$ of those for married for 20-29 age group (as opposed to $36 \%$ in the benchmark case) and about $26 \%$ for 30-39 age group (as opposed to $21 \%$ ).

What about the effect on children? Since more kids are born in the second period now, we expect those kids to receive more human capital investment. The fraction of kids who live with single mothers also changes. While in the benchmark economy about $27 \%$ of children live with a single mother, when we introduce returns to experience for women this number increased to $30 \%$. Although more kids are born in the second period and receive more human capital investment, more of them also live with single mothers. These two effects cancel each other and we observe no change in the human capital investment in children and hence no change in the long run productivity distribution. If we keep the fraction of kids living with single mothers constant and only change the timing, however, Table 9 implies that we would see a $2 \%$ rise in human capital investment. ${ }^{14}$

\subsection{The Gender Gap in Wages}

The wage gap between men and women has declined significantly since the 1970s. Blau and Khan (1997) find that women's wages rose on average from $62.2 \%$ to $72.4 \%$ of men's average wages between 1979 and 1988. Although an increase in returns to experience is partly responsible for this change, the gender gap in wages has also declined across all experience levels. What are the effects of a change in the pure wage gap in this model? In order to answer this question, we keep the returns to experience parameters the same as the benchmark values, but eliminate the wage gap. The results of this experiment, labelled experiment 2, are shown in Table 9. The effect on the timing of fertility is rather small. The change in marital status, however, is relatively large: the marriage rate declines from $68 \%$ to $59 \%$, and the proportion of young women who are single rises from 36 to $48 \%$.

Male labor supply as well as that of married women also decline by around $20 \%$. Aggregate effective labor therefore declines when women's wages increase; this reflects a

\footnotetext{
${ }^{14}$ As a robustness check, we ran some experiments with lower fertility rates for single women, by imposing a utility cost (or stigma) for having an out-of-wedlock birth. Our basic result regarding the shift in the timing of births with the introduction of returns to experience for women did not change.
} 
simple composition effect. Since a rise in female wages results in more single mothers, society ends up investing less in children, moving the population over time towards the lower end of the productivity distribution. For example, a single female of type- $x_{1}$ supplies 0.13 in the benchmark economy and 0.15 when the gender gap is eliminated, in the steady state with no gender gap about $18 \%$ of the population start their lives at the lowest end of the productivity distribution in contrast to only $5 \%$ in the benchmark case. Since the benefit of working is lower for people with low wages, this shift in the long-run distribution of human capital explains why there is a reduction in labor supply when women's wages increase. The last column in Table 9, labelled experiment 2f, confirms this results. Here we eliminate the wage gap, but keep the distribution of human capital at its benchmark level. Although people make investment in their kids, this has no effect on how the next generations' human capital is updated. Now we get the increase in labor supply that we expect.

\subsection{The Role of Fertility Timing}

To assess the importance of the timing margin, we present results from two pairs of experiments in which women were only permitted to have children in one period. In the first pair, women can have children only in the first period; in the other, women can have children only in the second. Each pair consists of a benchmark economy with no returns to experience for women, and an experiment in which returns to experience were shifted up by the same amount as in Experiment 1. Table 10 shows the results: the inability to shift fertility across periods results in a much smaller change in labor supply and a larger drop in fertility, regardless of which period fertility is allowed. Labor supply rises but by much smaller percentages than in the model with endogenous timing; in the second pair of experiments, by $10 \%$ for first-period women, and by only $5 \%$ for married women in the second period. Income inequality decreases by much less than when fertility timing is endogenous. This suggests that analysis which takes demographics as given will tend to significantly underestimate the long-term labor-market effects of changes in the returns to experience. Finally, the drop in average fertility is much greater when fertility is restricted to period 1 than to period 2, so aggregate quantities are sensitive to the way in which timing is suppressed. 


\subsection{The Marriage Market}

The fact that a change in the return to experience has a small effect on the marriage market is surprising in the context of the model, given the strong interactions between the marriage and labor markets. It seems plausible that this is due to bargaining between spouses, which stabilises marriages by allocating more utility to the partner whose outside option has increased most, in this case the wives. This is highlighted in our next experiment. Here we introduce the returns to experience to our benchmark economy as we did in experiment 1, but we use the weights that correspond to the Nash Bargaining problem from our benchmark economy. Therefore, changes in outside options cannot be reflected in the decisions of the couples. Potentially this has two effects: the fraction of marriages that are individually rational for both partners falls, so the marriage rate falls, and the bargaining power of women in the remaining marriages increases. In this experiment, both effects are shut down.

Specifically, we fix the marriage and divorce indicator functions as well as the bargaining power associated with each marriage at their benchmark values. We then change the returns to experience for women. We allow single men and women to behave optimally. However, marriages that did not occur in the benchmark case, are not permitted, even if they yield a positive surplus. On the other hand, marriages that did take place in the benchmark case are required, even if they don't yield a positive surplus. All decisions in these marriages are made taking as given the utility share implied by the Nash solution in the benchmark case. In this experiment we shut down both the marriage market and the effect of outside options on marital decisions.

In this experiment, we get a shift in the proportion of late births from $35 \%$ to $40 \%$ (as compared to $44 \%$ in our first experiment). The 4 percent difference represents the effect of better bargaining positions for women. Even if the same number of women are married in the aggregate, what happens within those marriages reflects the change in the returns to experience for women. Therefore, roughly one half of the aggregate effects of the change in returns to women's experience is due to the improvement in women's bargaining positions within marriage. 


\section{Conclusion}

The goal of this paper is to explore the nature of the interaction between the age at which women choose to become mothers and the evolution of the marriage market, female wages and labor supply. We develop a dynamic model of family formation that links marriage decisions and labor supply via the production of children, in which the three key margins are quality, quantity, and timing. In contrast to the previous literature on fertility dynamics, we allow for endogenous marital decisions, and solve for the marriage-market equilibrium. Although this inevitably entails considerable sacrifice in terms of the structure of the labor market and of the life-cycle, we are able to calibrate the model to US data under the assumption that each period of the model is equivalent to 10 years in the data.

From our calibrated model, we are able to generate a steady-state equilibrium which reproduces the most relevant features of the data for the 1948-57 cohort of women in the PSID. This includes the wage distribution across marital states, the fraction of women who get divorced in their 20's, the proportion of children with single mothers, and the proportion of children born after the mothers reach age 30. In addition, we are able to replicate the following qualitative features of the data: fertility and the divorce rate are declining in family income, and lower-wage women have children earlier.

An important issue in this area of research is explaining the remarkable changes in family structure and women's labor-market behavior observed in the U.S. over the last 40 years. These changes are reflected in the differences we observe in the PSID between the 1948-57 and the 1958-67 cohorts of women. We use the calibrated model to run a number of experiments to see whether introducing changes in women's wage structure into the benchmark model produces equilibrium results analogous to the changes observed across these two cohorts. We find that increasing the effect of labor-market experience on women's wages results in a large change in the timing of fertility; the proportion of children born after age 30 rises from 0.36 to 0.47 , but marriage rates remain relatively constant. Increasing women's wages on the other hand results in a large decline in marriage, and little change in the timing of births. Both experiments result in higher labor supply for women.

These results suggest that the change in the wage structure is indeed a plausible explanation of both facets of the change in women's behavior, but that the change is more complex than simply a closing of the wage gap, which is insufficient to explain the changes in the timing of fertility. Our timing results suggest that women in the more recent cohort 
perceived that their future wages were more responsive to their labor experience than was the case for the older cohorts, a hypothesis that is supported by the findings of Blau and Kahn (1997) and Olivetti (2000). The causes of this change are outside the scope of this research, but we believe this is consistent with the intense campaign waged by feminists and the government in the 1970's against sex-discrimination in not just wages but also promotions and job mobility.

The importance of the timing margin is highlighted by our results from a series of experiments in which women were only permitted to have children in one period. The inability to shift fertility across periods results in a much smaller change in labor supply. This suggests that analysis which takes demographics as given will tend to significantly underestimate the long-term labor-market effects of changes in the returns to experience. Furthermore, the results are sensitive to which period is allowed, suggesting that abstraction from this margin may yield results that are quite sensitive to the model's assumptions.

It is important to note the role played by women's bargaining power and the marriage market in these results. Repeating the above computational experiment with bargaining power fixed to the benchmark levels results in a reduction by $50 \%$ in the change in the timing of births; in the absence of adjustment of the bargaining positions of the women, the fraction of kids born after age 30 rises only to $44 \%$ as opposed to $47 \%$. Thus it is important in modelling these changes to allow for the effect on women's bargaining power within marriages.

The model does not replicate the degree of positive assortative matching seen in the U.S., and exaggerates the fertility of single women. We perform a number of other experiments to test the robustness of our basic results and illustrate properties of the model. We find that incorporating a stigma that reduces utility for single mothers, reduces their fertility but does not significantly affect the wage structure experiments. Reducing the altruism of step-fathers for their wife's children, and introducing divorce costs both tend to reduce the marriage rate. The altruism experiment drastically reduces the fertility of young married women, illustrating the importance of the threat of divorce in the model.

Finally, we also run a number of experiments to clarify the role of the evolution of the income distribution. Holding constant the distribution of adult agents over productivity levels, we find that reducing the step-father's altruism has much larger effects, but that the wage experiments are relatively unaffected. In general we find that allowing the distribution 
to evolve is most important when the experiments result in significant changes in human capital investment by parents.

To summarize, we believe our model is helpful for clarifying a number of economic issues related to the joint evolution of women's labor supply and the marriage market. In particular, our results suggest that the timing margin of fertility decisions plays a quantitatively important role in determining marriage rates and income inequality. The changes in family structure and women's labor supply referred to in our introduction, our results suggest, could be better understood if we could explain what forces were responsible for the observed changes in both the level of women's wages, and in the response of wages to women's labor experience.

\section{References}

\section{References}

[1] Altug, Sumru, and Miller, Robert A. "The Effect of Work Experience on Female Wages and Labor Supply. "The Review of Economic Studies, vol. 65 (July 1998): 45-85.

[2] Becker, Gary S. "A Theory of Marriage: Part I," Journal of Political Economy, 81 (July/August 1973): 813-846.

[3] Becker, Gary S. "A Theory of Marriage: Part II," Journal of Political Economy, 82 (March/April 1974): S11-S26.

[4] Chade, Hector and Ventura, Gustavo. "Taxes and Marriage: A Two-Sided Search Analysis," mimeo, 2001.

[5] Conesa, Juan Carlos. "Educational Attainment and Timing of Fertility Decisions." Manuscript. University of Minnesota, 1999.

[6] Cutler, David M. and Katz, Lawrence F. "Rising Inequality? Changes in the Distribution of Income and Consumption in the 1980s." American Economic Review, vol. 82 (May 1992): 546-551. 
[7] Eckstein, Zvi and Wolpin, Kenneth I. "Dynamic Labor Force Participation of Married Women and Endogenous Work Experience." The Review of Economic Studies, vol. 56 (July 1989): 375-390.

[8] Erosa, Andres, Fuster, Luisa and Restuccia, Diego. "A General Equilibrium Model of Parental Leave Policies," mimeo, 2001.

[9] Fernandez, Raquel, and Rogerson, Richard. "Sorting and Long-Run Inequality." Quarterly Journal of Economics, forthcoming.

[10] Greenwood, Jeremy, Guner, Nezih, and Knowles, John "More on Marriage, Fertility, and the Distribution of Income." mimeo, 2000.

[11] Gruber, Johnathan, "Is Making Divorce Easier Bad for Children? The Long-Run Implications of Unilateral Divorce". NBER Working Paper \#7968, 2000.

[12] Gunderson, Morley. "Male-Female Wage Differentials and Policy Responses." Journal of Economic Literature, vol. XXVII (March 1989): 46-72.

[13] Heckman, James J. and Walker, James R. "The Relationship Between Wages and Income and the Timing and Spacing of Births: Evidence from Swedish Longitudinal Data," Econometrica, vol. 58 (November 1990): 1411-1141.

[14] Hotz, V. Joseph and Miller, Robert A. "An Empirical Analysis of Life Cycle Fertility and Female Labor Supply." Econometrica, vol. 56 (January 1988): 91-118.

[15] Hotz, V. Joseph, Klerman, Jacob A. and Willis, Robert J. "The Economics of Fertility in Developed Countries," in Handbook of Population and Family Economics, ed. by M. R. Rosenzweig and O. Stark. Elsevier Science, 1997.

[16] Knowles, John. "Social Policy, Equilibrium Poverty, and Investment in Children." Manuscript. Philadelphia, Pennsylvania: University of Pennsylvania, Department of Economics, 1999.

[17] Lewis, C. and Ventura, S. "Birth and Fertility Rates by Education: 1980 and 1985." Vital and Health Statistics 21(49), Hyattsville, MD, National Center for Health Statistics, 1990. 
[18] Mare, R. "Changes in Educational Attainment and School Enrollment," in The State of the Union: America in the 1990s, ed. by R. Farley. New York: Russell Sage Foundation, 1995.

[19] Moffitt, Robert. "The Estimation of a Joint Wage-Hours Labor Supply Model." Journal of Labor Economics, vol. 2 (October 1984): 550-566.

[20] Morgan, S. Philip. "Characteristic Features of Modern American Fertility," in Fertility in The United States: New Patterns, New Theories, ed. by John B. Casterline, Ronald D. Lee, and Karen A. Foote, The Population Council, New York, 1996,

[21] Mullin, Charles H and Wang, Ping. "The Timing of Childbearing and Human Capital Investment with Ability Heterogeneity." Manuscript. Nashville, Tennessee: Vanderbilt University, Department of Economics, 2001.

[22] Olivetti, Claudia. "Changes in Women's labor force participation: The effect of changing returns to experience." Manuscript. Philadelphia, Pennsylvania: University of Pennsylvania, Department of Economics, 2000.

[23] Olson, Lawrance. Costs of Children, Lexington Books, Lexington, Massachusetts, 1983.

[24] Regalia, Ferdinando, and Rios-Rull, Jose-Victor. "What Accounts for the Increase in Single Households and the Stability of Fertility?" Manuscript. UniversitatPompeuFabra,1999.

[25] Restuccia, Diego and Urrutia, Carlos, "Intergenerational Persistence of Economic Status: Sources and Policy," mimeo, 2001.

[26] Rindfuss, Ronald R., Morgan, S. Philip, and Offutt, Kate. "Education and The Changing Age Pattern of American Fertility: 1963-1989," Demography, vol. 22 (August 1996): $277-290$.

[27] Shimer, R. and L. Smith, "Assortative Matching and Search," Econometrica, vol.68 (2000): 343-370.

[28] Waldfogel, Jane. "Understanding the "Family Gap" in Pay for Women with Children." Journal of Economic Perspectives, vol. 12 (Winter 1998): 137-156. 


\section{Appendix A: Computation}

Consider the following weighted Pareto problem when the number of new children, $k$, is fixed:

$$
\max _{l, n, t, g} \rho M\left(c, h, 0, k, 1-n-\chi_{m}\left(k, k_{2}\right)\right)+(1-\rho) F\left(c, h, 0, k, 1-l-t-\chi_{f}\left(k, k_{2}\right)\right)
$$

subject to

$$
\begin{gathered}
c=\Psi\left(2, k+k_{2}\right)[x l+z n-g], \\
h=H\left(g, t, k, k_{2}\right) .
\end{gathered}
$$

When $\rho(k)=\frac{F(k)-G}{M(k)-B+F(k)-G}$, the solution to the weighted Pareto problem corresponds to the solution of the Nash Bargaining problem. This is demonstrated by comparing the first-order conditions associated with two problems.

To solve the Pareto problem we search for the Pareto weight that satisfies the above condition. We limit this search to the range of weights that gives rise to a positive marital surplus for both the potential husband and wife. Given the solution to the Pareto problem with the fixed fertility decision, we choose the integer number of children that maximizes the Nash Product:

$$
\max _{k}[F(k)-G][M(k)-B]
$$

\section{Appendix B: Concavity}

This is a proof of concavity of the continuation utility for a given specification of continuation probabilities. We assume the following specification for the probabilities (for simplicity it is assumed here are there are four possible productivity levels one can end up next period as a function of her/his labor):

$$
\begin{aligned}
& \pi_{2}(n)=a_{2}\left(1-n^{b}\right) \\
& \pi_{3}(n)=a_{3}\left(1-n^{b}\right) \\
& \pi_{4}(n)=a_{4} n^{b} \\
& \pi_{5}(n)=a_{5} n^{b}
\end{aligned}
$$

where $a_{2}+a_{3}=1, a_{4}+a_{5}=1$, and $0<b<1$. 
The next period's utility for an individual who works $n$ this period is given by:

$$
U(n)=\pi_{2}(n) U_{2}+\pi_{3}(n) U_{3}+\pi_{4}(n) U_{4}+\pi_{5}(n) U_{5}
$$

where $U_{5}>U_{4}>U_{3}>U_{2}$ are the utilities associated with different grid points. The derivative of this utility with respect to $n$ is given by:

$$
\frac{\partial U(n)}{\partial n}=\frac{\partial \pi_{2}(n)}{\partial n} U_{2}+\frac{\partial \pi_{3}(n)}{\partial n} U_{3}+\frac{\partial \pi_{4}(n)}{\partial n} U_{4}+\frac{\partial \pi_{5}(n)}{\partial n} U_{5}
$$

Given the functional forms for probability that we have chosen this can be written as:

$$
\frac{\partial U(n)}{\partial n}=b n^{b-1}\left[\left(a_{5} U_{5}+a_{4} U_{4}\right)-\left(a_{3} U_{3}+a_{2} U_{2}\right)\right]>0 .
$$

Since $a_{4}+a_{5}=1$, and $U_{5}>U_{4}$, we have $U_{5}>a_{5} U_{5}+a_{4} U_{4}>U_{4}$. Similarly, $U_{3}>$ $a_{3} U_{3}+a_{2} U_{2}>U_{2}$. Putting these two statements together, we have $a_{5} U_{5}+a_{4} U_{4}>a_{3} U_{3}+$ $a_{2} U_{2}$, making the derivative positive.

We take the second derivative in the same fashion, differentiating each probability twice, multiplying by the corresponding utility and summing, we have

$$
\frac{\partial^{2} U(n)}{\partial n^{2}}=b(b-1) n^{b-2}\left[\left(a_{5} U_{5}+a_{4} U_{4}\right)-\left(a_{3} U_{3}+a_{2} U_{2}\right)\right]<0,
$$

since $a_{5} U_{5}+a_{4} U_{4}>a_{3} U_{3}+a_{2} U_{2}$. 


\section{Table 1: PSID Women aged 1 to 50 in 1968 by Income Quintile}

\begin{tabular}{|c|c|c|c|c|c|c|c|c|c|c|c|c|}
\hline $\begin{array}{l}\text { Income } \\
\text { Quintile }\end{array}$ & $\begin{array}{l}\text { Number } \\
\text { of Obs. }\end{array}$ & Statistic & $\begin{array}{c}\text { Age at } \\
\text { First } \\
\text { Child }\end{array}$ & $\begin{array}{l}\text { Age at } \\
\text { 2nd } \\
\text { Child }\end{array}$ & $\begin{array}{l}\text { Child } \\
\text { before } \\
\text { Age } 20\end{array}$ & $\begin{array}{l}\text { Number } \\
\text { of Kids by } \\
\text { Age } 20\end{array}$ & $\begin{array}{l}\text { Proportion } \\
\text { of kids born } \\
\text { after age } \\
30\end{array}$ & $\begin{array}{l}\text { Single } \\
\text { Moms }\end{array}$ & $\begin{array}{c}\text { Divorced } \\
\text { Moms }\end{array}$ & $\begin{array}{l}\text { Number of } \\
\text { Kids Ever }\end{array}$ & $\begin{array}{c}\text { Got } \\
\text { Divorced } \\
\text { in age } 20- \\
\text { age } 30\end{array}$ & $\begin{array}{c}\text { Got } \\
\text { Divorced } \\
\text { in age } 30- \\
40\end{array}$ \\
\hline \multirow{4}{*}{1} & \multirow{3}{*}{375} & mean & 20.873 & 24.798 & 0.461 & 0.392 & 0.374 & 0.272 & 0.283 & 2.933 & 0.144 & 0.16 \\
\hline & & std. & 4.772 & 4.999 & 0.499 & 0.93 & 0.293 & 0.446 & 0.451 & 2.613 & 0.352 & 0.367 \\
\hline & & nobs & 299 & 129 & 375 & 375 & 299 & 375 & 375 & 375 & 375 & 375 \\
\hline & \multirow{3}{*}{375} & mean & 21.93 & 25.228 & 0.355 & 0.339 & 0.363 & 0.133 & 0.232 & 2.509 & 0.149 & 0.173 \\
\hline \multirow[t]{2}{*}{2} & & std. & 4.246 & 4.587 & 0.479 & 0.887 & 0.293 & 0.34 & 0.423 & 2.076 & 0.357 & 0.379 \\
\hline & & nobs & 301 & 101 & 375 & 375 & 301 & 375 & 375 & 375 & 375 & 375 \\
\hline \multirow{3}{*}{3} & \multirow{3}{*}{373} & mean & 22.648 & 24.586 & 0.343 & 0.271 & 0.371 & 0.11 & 0.198 & 2.525 & 0.094 & 0.142 \\
\hline & & std. & 4.748 & 4.053 & 0.475 & 0.699 & 0.283 & 0.313 & 0.399 & 1.635 & 0.292 & 0.35 \\
\hline & & nobs & 327 & 99 & 373 & 373 & 327 & 373 & 373 & 373 & 373 & 373 \\
\hline \multirow{3}{*}{4} & \multirow{3}{*}{375} & mean & 23.049 & 25.288 & 0.293 & 0.224 & 0.395 & 0.083 & 0.131 & 2.472 & 0.08 & 0.083 \\
\hline & & std. & 4.419 & 3.662 & 0.456 & 0.648 & 0.256 & 0.276 & 0.337 & 1.352 & 0.272 & 0.276 \\
\hline & & nobs & 347 & 66 & 375 & 375 & 347 & 375 & 375 & 375 & 375 & 375 \\
\hline \multirow{3}{*}{5} & \multirow{3}{*}{371} & mean & 24.459 & 27.676 & 0.221 & 0.278 & 0.45 & 0.057 & 0.07 & 2.358 & 0.054 & 0.035 \\
\hline & & std. & 4.792 & 3.712 & 0.415 & 0.667 & 0.28 & 0.231 & 0.256 & 1.268 & 0.226 & 0.184 \\
\hline & & & & & & & & & & & 371 & 371 \\
\hline
\end{tabular}




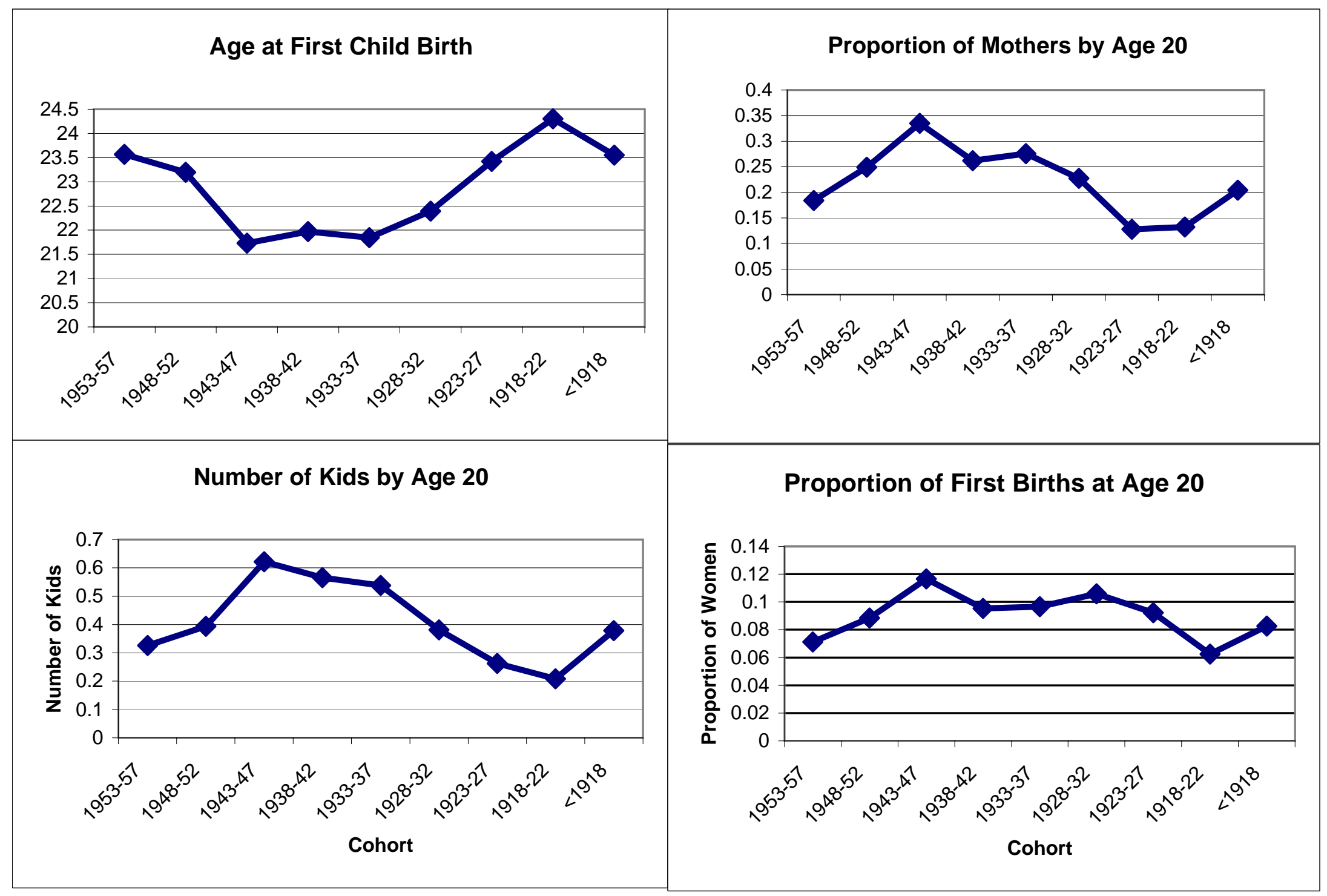

Figure 1: Time trends in measures of the timing of fertility. Based on author's computations on mothers from the representative crosssection of the PSID. 
Table 2: PSID Women aged 1 to 50 in 1968 by Cohort

\begin{tabular}{|c|c|c|c|c|c|c|c|c|c|c|}
\hline $\begin{array}{l}\text { Birth } \\
\text { Date }\end{array}$ & Statistic & $\begin{array}{l}\text { Number } \\
\text { of Obs. }\end{array}$ & $\begin{array}{l}\text { Age at } \\
\text { First } \\
\text { Child }\end{array}$ & $\begin{array}{l}\text { Child } \\
\text { before } \\
\text { Age } 20\end{array}$ & $\begin{array}{c}\text { No Child } \\
\text { by Age } \\
30\end{array}$ & $\begin{array}{c}\text { No Child } \\
\text { by age } \\
40\end{array}$ & $\begin{array}{l}\text { Proportion } \\
\text { of kids born } \\
\text { after age } 30\end{array}$ & $\begin{array}{l}\text { Single } \\
\text { Moms }\end{array}$ & $\begin{array}{l}\text { Divorced } \\
\text { Moms }\end{array}$ & $\begin{array}{l}\text { Number } \\
\text { of Kids } \\
\text { Ever }\end{array}$ \\
\hline \multirow{4}{*}{$1960-67$} & mean & & 23.018 & 0.323 & 0.23 & 0.156 & 0.409 & 0.184 & 0.323 & 1.989 \\
\hline & std. & 538 & 4.999 & 0.468 & 0.422 & 0.363 & 0.275 & 0.388 & 0.468 & 1.26 \\
\hline & nobs & & 454 & 538 & 538 & 538 & 454 & 538 & 538 & 538 \\
\hline & mean & & 21.809 & 0.402 & 0.126 & 0.085 & 0.364 & 0.108 & 0.173 & 2.859 \\
\hline \multirow[t]{2}{*}{$1950-59$} & std. & 768 & 4.204 & 0.491 & 0.332 & 0.279 & 0.263 & 0.311 & 0.379 & 1.877 \\
\hline & nobs & & 703 & 768 & 768 & 768 & 703 & 768 & 768 & 768 \\
\hline
\end{tabular}


Table 3a: Actual Timing of Fertility

\begin{tabular}{|c|c|c|c|c|c|c|}
\hline \multirow{2}{*}{$\begin{array}{l}\text { Years of } \\
\text { Education }\end{array}$} & \multicolumn{3}{|c|}{ 1960's Cohort } & \multicolumn{3}{|c|}{ 1950's Cohort } \\
\hline & Mass & Age & Prop. $>30$ & Mass & Age & Prop. > 30 \\
\hline$<12$ & 0.08364 & 18.364 & 0.030864 & 0.16536 & 19.182 & 0.0537435 \\
\hline 12 & 0.54647 & 21.537 & 0.188532 & 0.60807 & 21.766 & 0.2182982 \\
\hline $13-16$ & 0.20818 & 26.261 & 0.100134 & 0.1276 & 23.955 & 0.0495104 \\
\hline$>16$ & 0.16171 & 27.825 & 0.096541 & 0.09896 & 24.566 & 0.0457188 \\
\hline Average & & 23.2719 & 0.416071 & & 21.8951 & 0.3672708 \\
\hline
\end{tabular}

Table 3b: Counterfactual Timing of Fertility

\begin{tabular}{|c|c|c|c|c|c|c|}
\hline \multirow{2}{*}{$\begin{array}{l}\text { Years of } \\
\text { Education }\end{array}$} & \multicolumn{3}{|c|}{$\begin{array}{c}\text { 1950's Mass with 1960's } \\
\text { Behavior }\end{array}$} & \multicolumn{3}{|c|}{$\begin{array}{c}\text { 1960's Mass with 1950's } \\
\text { Behavior }\end{array}$} \\
\hline & Mass & Age & Prop. $>30$ & Mass & Age & Prop. > 30 \\
\hline$\overline{<12}$ & 0.08364 & 19.182 & 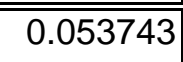 & 0.16536 & 3.17202 & 0.0537435 \\
\hline 12 & 0.54647 & 21.766 & 0.218298 & 0.60807 & 13.2353 & 0.2182982 \\
\hline $13-16$ & 0.20818 & 23.955 & 0.04951 & 0.1276 & 3.05676 & 0.0495104 \\
\hline$>16$ & 0.16171 & 24.566 & 0.045719 & 0.09896 & 2.43101 & 0.0457188 \\
\hline Average & & 22.2374 & 0.39126 & & 22.4584 & 0.3788494 \\
\hline
\end{tabular}


Table 4a: Women born 1958-1967

\begin{tabular}{|c|c|c|c|c|c|c|c|}
\hline $\begin{array}{c}\text { Age } \\
\text { Interval }\end{array}$ & $\begin{array}{l}\text { Marital } \\
\text { Status }\end{array}$ & Statistic & $\begin{array}{c}\text { Annual } \\
\text { Hours }\end{array}$ & $\begin{array}{l}\text { Annual } \\
\text { Labor }\end{array}$ & $\begin{array}{c}\text { Total } \\
\text { Family } \\
\end{array}$ & $\begin{array}{c}\text { Spouses } \\
\text { Annual }\end{array}$ & $\begin{array}{l}\text { Other } \\
\text { Family }\end{array}$ \\
\hline \multirow{6}{*}{$16-19$} & \multirow{3}{*}{ Single } & mean & 9940 & "3763.01 & 8140.48 & 0 & "4377.47 \\
\hline & & std. & 794.02 & 3590.12 & 5828.81 & 0 & 5613.62 \\
\hline & & nobs & 25 & 25 & 25 & 25 & 25 \\
\hline & \multirow{3}{*}{ Married } & mean & 483.7 & 1843.59 & 14585.6 & 11344.03 & 12742.01 \\
\hline & & std. & 608.03 & 2323 & 7705.67 & 8040.47 & 7430.6 \\
\hline & & nobs & 57 & 57 & 57 & 57 & 57 \\
\hline \multirow{6}{*}{$20-29$} & \multirow{3}{*}{ Single } & mean & 1325.93 & 7324.81 & 10013.48 & 0 & 2688.66 \\
\hline & & std. & 928.12 & 6896.43 & 7743.51 & 0 & 4705.39 \\
\hline & & nobs & 247 & 247 & 247 & 247 & 247 \\
\hline & \multirow{3}{*}{ Married } & mean & 1048.33 & 6047.88 & 22390.35 & 13750.11 & 16342.48 \\
\hline & & std. & 859.88 & 6294.2 & 12949.48 & 11431.46 & 11338.75 \\
\hline & & nobs & 870 & 870 & 870 & 870 & 870 \\
\hline \multirow{6}{*}{$30-40$} & \multirow{4}{*}{ Single } & mean & 1280.17 & 9980.53 & 11759.12 & 0 & 1778.59 \\
\hline & & std. & 935.19 & 9656.65 & 9423.67 & 0 & 3819.87 \\
\hline & & nobs & 163 & 163 & 163 & 163 & 163 \\
\hline & & mean & 1282.7 & 9344.45 & 30136.06 & 16566.57 & 20791.61 \\
\hline & \multirow[t]{2}{*}{ Married } & std. & 918.13 & 8840.71 & 21719.54 & 15688.76 & 20259.88 \\
\hline & & nobs & 1030 & 1030 & 1030 & 1030 & 1030 \\
\hline
\end{tabular}

Table 4b: Women born 1948-1957

\begin{tabular}{|c|c|c|c|c|c|c|c|}
\hline $\begin{array}{c}\text { Age } \\
\text { Interval }\end{array}$ & $\begin{array}{l}\text { Marital } \\
\text { Status }\end{array}$ & Statistic & $\begin{array}{l}\text { Annual } \\
\text { Hours } \\
\text { Worked }\end{array}$ & $\begin{array}{l}\text { Annual } \\
\text { Labor } \\
\text { Income }\end{array}$ & $\begin{array}{l}\text { Total } \\
\text { Family } \\
\text { Income }\end{array}$ & $\begin{array}{c}\text { Spouses } \\
\text { Annual } \\
\text { Labor } \\
\text { Income }\end{array}$ & $\begin{array}{l}\text { Other } \\
\text { Family } \\
\text { Income }\end{array}$ \\
\hline \multirow{6}{*}{$16-19$} & \multirow{4}{*}{ Single } & mean & 946.56 & 4001.03 & 6666.54 & 24.04 & 2665.5 \\
\hline & & std. & 773.93 & 4652.56 & 6756.38 & 313.48 & 4661.47 \\
\hline & & nobs & 170 & 170 & 170 & 170 & 170 \\
\hline & & mean & 578.04 & 2440.77 & 14540.1 & 11311.6 & 12099.32 \\
\hline & \multirow[t]{2}{*}{ Married } & std. & 695.49 & 3275.34 & 7156.21 & 6403.68 & 6178.31 \\
\hline & & nobs & 455 & 455 & 455 & 455 & 455 \\
\hline \multirow{9}{*}{$20-29$} & \multirow{3}{*}{ Single } & mean & 1227.37 & 7550.21 & 10316.06 & 0 & 2765.85 \\
\hline & & std. & 893.04 & 6922.29 & 6692.29 & 0 & 4370.29 \\
\hline & & nobs & 2596 & 2596 & 2596 & 2596 & 2596 \\
\hline & \multirow{4}{*}{ Married } & mean & 1016.49 & 6086.16 & 23228.7 & 14829.01 & 17142.55 \\
\hline & & std. & 863.06 & 6316.96 & 13025.9 & 10917.08 & 11533.71 \\
\hline & & nobs & 7429 & 7429 & 7429 & 7429 & 7429 \\
\hline & & mean & 962.34 & 4248.5 & 13461.16 & 5239.7 & 9212.66 \\
\hline & \multirow[t]{2}{*}{ Divorced } & std. & 850.39 & 4205.91 & 8360.3 & 8161.54 & 8213.24 \\
\hline & & nobs & 190 & 190 & 190 & 190 & 190 \\
\hline \multirow{9}{*}{$30-40$} & \multirow{3}{*}{ Single } & mean & 1275.85 & 9733.88 & 12801.41 & 0 & 3067.53 \\
\hline & & std. & 954.99 & 10314.62 & 11586.32 & 0 & 6052.9 \\
\hline & & nobs & 2010 & 2010 & 2010 & 2010 & 2010 \\
\hline & \multirow{3}{*}{ Married } & mean & 1263.8 & 9567.51 & 31962.7 & 18037.81 & 22395.19 \\
\hline & & std. & 901.32 & 9828.52 & 25614.67 & 19049.05 & 23230.83 \\
\hline & & nobs & 9203 & 9203 & 9203 & 9203 & 9203 \\
\hline & \multirow{3}{*}{ Divorced } & mean & 1362.15 & 7977.11 & 20275.03 & 7637.22 & 12297.92 \\
\hline & & std. & 953.02 & 6932.63 & 12693.78 & 9601.35 & 10512.01 \\
\hline & & nobs & 310 & 310 & 310 & 310 & 310 \\
\hline
\end{tabular}


Table 5a: Men born 1958-1967

\begin{tabular}{|c|c|c|c|c|c|c|c|}
\hline $\begin{array}{c}\text { Age } \\
\text { Interval }\end{array}$ & $\begin{array}{l}\text { Marital } \\
\text { Status }\end{array}$ & Statistic & $\begin{array}{l}\text { Annual } \\
\text { Hours } \\
\text { Worked }\end{array}$ & $\begin{array}{l}\text { Annual } \\
\text { Labor } \\
\text { Income }\end{array}$ & $\begin{array}{c}\text { Total } \\
\text { Family } \\
\text { Income }\end{array}$ & $\begin{array}{c}\text { Spouses } \\
\text { Annual } \\
\text { Labor } \\
\text { Income }\end{array}$ & $\begin{array}{l}\text { Other } \\
\text { Family } \\
\text { Income }\end{array}$ \\
\hline \multirow{6}{*}{$16-19$} & \multirow{3}{*}{ Single } & mean & 1452.68 & 5990.11 & 7021.33 & 0 & 1031.22 \\
\hline & & std. & 883.77 & 4753.93 & 5250.24 & 0 & 2321.13 \\
\hline & & nobs & 19 & 19 & 19 & 19 & 19 \\
\hline & \multirow{3}{*}{ Married } & mean & 1552.63 & 6512.41 & 8099.44 & 1253.99 & 1587.02 \\
\hline & & std. & 507.6 & 3881.7 & 3874.67 & 1276.34 & 1430.01 \\
\hline & & nobs & 8 & 8 & 8 & 8 & 8 \\
\hline \multirow{6}{*}{$20-29$} & \multirow{4}{*}{ Single } & mean & 1766.11 & 12682 & 14622.54 & 0 & 1940.54 \\
\hline & & std. & 747.75 & 7764.8 & 8670.38 & 0 & 4048.17 \\
\hline & & nobs & 276 & 276 & 276 & 276 & 276 \\
\hline & & mean & 1900.9 & 13532.04 & 20783.15 & 4951.5 & 7251.11 \\
\hline & \multirow[t]{2}{*}{ Married } & std. & 901.38 & 9304.79 & 12126 & 6845.99 & 7844.41 \\
\hline & & nobs & 527 & 527 & 527 & 527 & 527 \\
\hline \multirow{6}{*}{$30-40$} & \multirow{4}{*}{ Single } & mean & 1678.65 & 15610.58 & 18164.12 & 0 & 2553.54 \\
\hline & & std. & 871.94 & 11282 & 13320.48 & 0 & 8462.55 \\
\hline & & nobs & 125 & 125 & 125 & 125 & 125 \\
\hline & & mean & 2067.47 & 19940.75 & 31447.77 & 8330.75 & 11507.02 \\
\hline & \multirow[t]{2}{*}{ Married } & std. & 803.39 & 14061.65 & 20071.56 & 10185.74 & 13590.02 \\
\hline & & nobs & 841 & 841 & 841 & 841 & 841 \\
\hline
\end{tabular}

Table 5b: Men born 1948-1957

\begin{tabular}{|c|c|c|c|c|c|c|c|}
\hline $\begin{array}{c}\text { Age } \\
\text { Interval }\end{array}$ & $\begin{array}{l}\text { Marital } \\
\text { Status }\end{array}$ & Statistic & $\begin{array}{c}\text { Annual } \\
\text { Hours } \\
\text { Worked }\end{array}$ & $\begin{array}{l}\text { Annual } \\
\text { Labor } \\
\text { Income }\end{array}$ & $\begin{array}{l}\text { Total } \\
\text { Family } \\
\text { Income }\end{array}$ & $\begin{array}{l}\text { Spouses } \\
\text { Annual } \\
\text { Labor } \\
\text { Income }\end{array}$ & $\begin{array}{l}\text { Other } \\
\text { Family } \\
\text { Income }\end{array}$ \\
\hline \multirow{6}{*}{$16-19$} & \multirow{4}{*}{ Single } & mean & $\begin{array}{l}1297.28 \\
\end{array}$ & 5626.36 & 7203.03 & 0 & 1576.67 \\
\hline & & std. & 887.74 & 4638.17 & 6529.76 & 0 & 4481.92 \\
\hline & & nobs & 93 & 93 & 93 & 93 & 93 \\
\hline & & mean & 1775.25 & 9327.82 & 12121.84 & 1997.5 & 2794.02 \\
\hline & \multirow[t]{2}{*}{ Married } & std. & 718.11 & 5711.43 & 6866.14 & 3045.27 & 4244.08 \\
\hline & & nobs & 127 & 127 & 127 & 127 & 127 \\
\hline \multirow{9}{*}{$20-29$} & \multirow{3}{*}{ Single } & mean & 1678.62 & 11739.54 & 13740.17 & 8.84 & 2000.63 \\
\hline & & std. & 859.51 & 9149.62 & 10310.48 & 394.03 & 4405.93 \\
\hline & & nobs & 1987 & 1987 & 1987 & 1987 & 1987 \\
\hline & \multirow{4}{*}{ Married } & mean & 2037.44 & 16103.46 & 22748.63 & 4943.9 & 6645.17 \\
\hline & & std. & 732.83 & 9462.46 & 12366.71 & 6156.98 & 7166.1 \\
\hline & & nobs & 5559 & 5559 & 5559 & 5559 & 5559 \\
\hline & & mean & 1997.96 & 17223.36 & 19982.2 & 1638.51 & 2758.84 \\
\hline & \multirow[t]{2}{*}{ Divorced } & std. & 676.06 & 7385.65 & 8581.58 & 3627.38 & 4099.18 \\
\hline & & nobs & 45 & 45 & 45 & 45 & 45 \\
\hline \multirow{9}{*}{$30-40$} & \multirow{3}{*}{ Single } & mean & 1651.86 & 14243.06 & 17037.48 & 0 & 2794.42 \\
\hline & & std. & 968.76 & 15406.06 & 17988.58 & 0 & 6916.23 \\
\hline & & nobs & 1174 & 1174 & 1174 & 1174 & 1174 \\
\hline & \multirow{4}{*}{ Married } & mean & 2089.4 & 21714.53 & 31584.02 & 7069.56 & 9869.49 \\
\hline & & std. & 763.23 & 17925.9 & 22719.46 & 9214.5 & 11529.32 \\
\hline & & nobs & 8314 & 8314 & 8314 & 8314 & 8314 \\
\hline & & mean & 2010.03 & 20999.05 & 28427.31 & 5695.85 & 7428.26 \\
\hline & \multirow[t]{2}{*}{ Divorced } & std. & 786.12 & 10657.87 & 9626.57 & 7633.07 & 7841.13 \\
\hline & & nobs & 70 & 70 & 70 & 70 & 70 \\
\hline
\end{tabular}




\section{Table 6: Benchmark Economy}

Statistics

Model Data Data Source

Timing of Births

$\%$ of kids born after age 30

35

36

1950-1959 birth cohort from PSID

(Table 2)

Marital Status of Population

$\begin{array}{rrr}\text { married (\%) } & 68 & 73 \\ \text { single (\%) } & 32 & 26\end{array}$

Marital Status of Females, 1969-79 average

Fertility

$\begin{array}{llll}\text { TFR } & 2.3 & 2.1 & \text { TFR for } 1970 \text { from NCHS }\end{array}$

Income Inequality

Income of single females income for married females

20-29

30-39

0.36

0.21

Labor Supply

$\begin{array}{rll}\text { Single Men } & & \\ 20-29 & 0.41 & 0.33 \\ 30-39 & 0.33 & 0.33 \\ \text { Single Women } & & \\ 20-29 & 0.24 & 0.24 \\ 30-39 & 0.20 & 0.25 \\ \text { Married Men } & & \\ 20-29 & 0.48 & 0.41 \\ 30-39 & 0.47 & 0.43 \\ \text { Married Women } & & \\ 20-29 & 0.13 & 0.19 \\ 30-39 & 0.13 & 0.24\end{array}$

1948-1957 birth cohort from PSID

(Table $3 \mathrm{~b}$ and $4 \mathrm{~b}$, with total time endowment being normalized to 5000 hours per year)

1948-1957 birth cohort from PSID

(Table 3b)

Wage Growth for Married

From 20-29 to 30-39, \%

Males $\quad 43$

39

1948-1957 birth cohort from PSID

(Table 4b)

Investment in Kids

Average Income Share Spent on Kids (\%) $14 \quad 14 \quad$ Olson (1983) 


\section{Table 7: Fertility Decisions in Benchmark Economy}

total number of kids per female (born in the second period, born in the first period)

Aggregate

$2.27(.78,1.49)$

\begin{tabular}{|c|c|c|c|c|}
\hline & \multirow{2}{*}{$\begin{array}{l}\text { Productivity } \\
\text { Type }\end{array}$} & \multicolumn{3}{|c|}{ Marital Status in the Second Model Period } \\
\hline & & Single & New Marriage & Old Marriage \\
\hline mother's & $x=1$ & $3.79(2.00,1.79)$ & $2.57(.69,1.88)$ & $2.36(.36,2.00)$ \\
\hline productivity & $x=2$ & $3.00(1.36,1.64)$ & $2.60(.831 .77)$ & $2.20(.20,2.00)$ \\
\hline in the second & $x=3$ & $2.54(1.00,1.54)$ & $2.40(.72,1.68)$ & $2.19(.19,2.00)$ \\
\hline model & $x=4$ & $2.55(1.00,1.55)$ & $2.34(.65,1.69)$ & $2.33(.35,1.98)$ \\
\hline \multirow[t]{3}{*}{ period } & $x=5$ & $2.00(1.00,1.00)$ & $1.90(.90,1.00)$ & $2.00(1.00,1.00)$ \\
\hline & $x=6$ & $2.00(1.00,1.00)$ & $1.85(.85,1.00)$ & $2.00(1.00,1.00)$ \\
\hline & $x=7$ & $1.00(0.00,1.00)$ & $1.66(.66,1.00)$ & $1.88(.88,1.00)$ \\
\hline father's & $\mathrm{Z}=1$ & & $2.86(1.21,1.65)$ & \\
\hline productivity & $z=2$ & & $2.50(1.05,1.46)$ & \\
\hline in the second & $z=3$ & & $2.48(1.05,1.43)$ & $2.66(1.00,1.66)$ \\
\hline model & $z=4$ & & $2.48(1.05,1.43)$ & $2.66(1.00,1.66)$ \\
\hline \multirow[t]{3}{*}{ period } & $z=5$ & & $2.01(.45,1.56)$ & $1.97(.34,1.63)$ \\
\hline & $z=6$ & & $2.07(.55,1.51)$ & $2.00(.40,1.60)$ \\
\hline & $\mathrm{Z}=7$ & & $1.66(.06,1.60)$ & $1.99(.52,1.47)$ \\
\hline $\begin{array}{l}\text { Fertility } \\
\text { by Marital Status }\end{array}$ & & $2.41(1.04,1.37)$ & $2.27(.75,1.52)$ & $2.17(.54,1.63)$ \\
\hline $\begin{array}{l}\text { Measure of } \\
\text { Females } \\
\text { by Marital Status }\end{array}$ & & 0.36 & 0.32 & 0.31 \\
\hline
\end{tabular}


Table 8: Timing of Births in Benchmark Economy Fraction of Kids Born in the Second Period

(by marital status and productivity levels of parents)

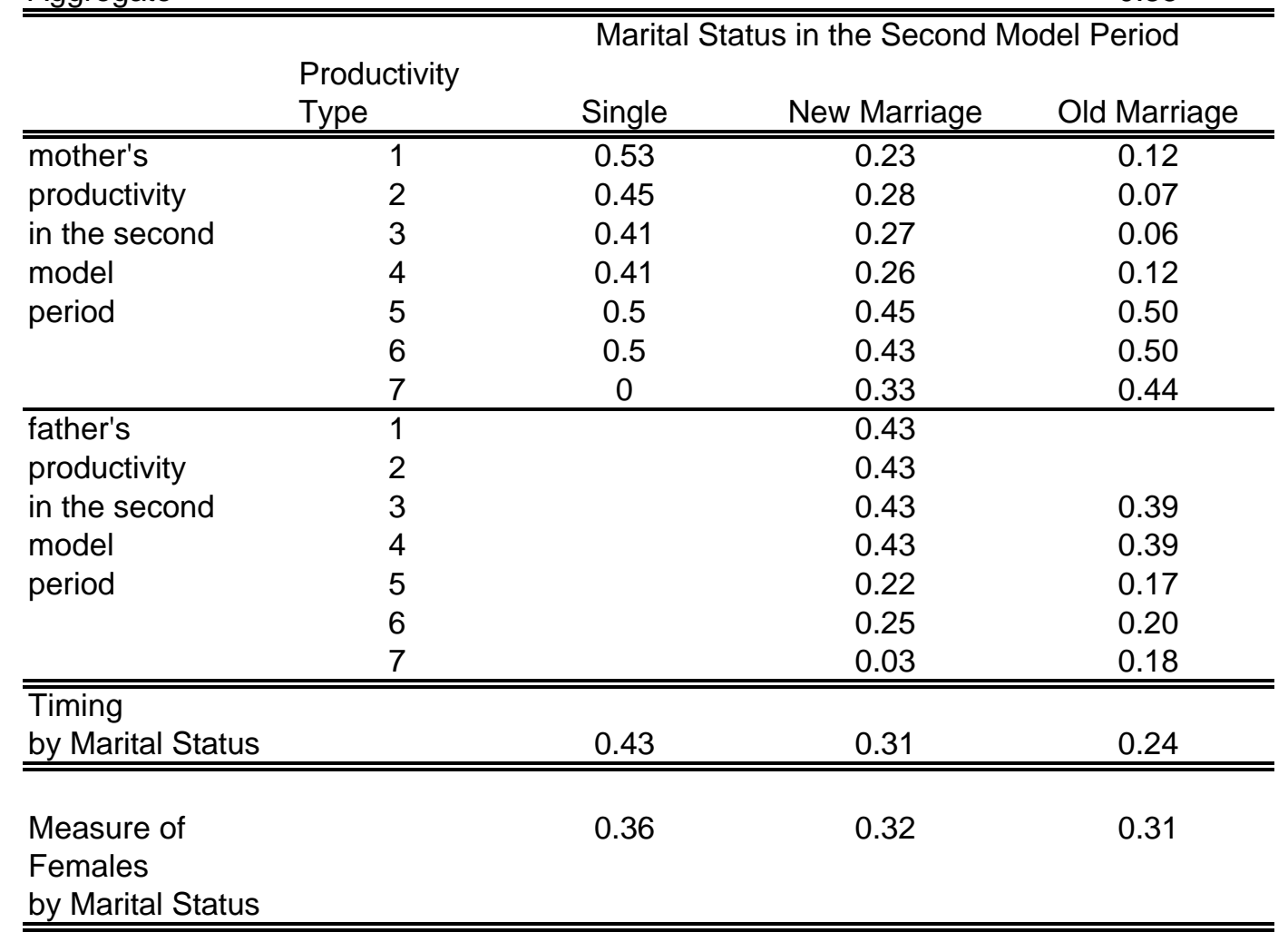


Table 9: Experiments

Statistics

Benchmark Experiment 1 Experiment 2 Experiment $2 f$ (fixed human cap.)

\begin{tabular}{|c|c|c|c|c|c|}
\hline \multicolumn{6}{|l|}{ Timing of Births } \\
\hline & $\%$ of kids born after age 30 & 35 & 44 & 37 & 37 \\
\hline \multicolumn{6}{|c|}{ Marital Status of Population } \\
\hline & married (\%) & 68 & 67 & 59 & 65 \\
\hline & single (\%) & 32 & 33 & 41 & 35 \\
\hline
\end{tabular}

Fertility

$\begin{array}{lllll}\text { TFR } & 2.3 & 2.3 & 2.3 & 2.1\end{array}$

Income Inequality

Income of single females Income of married females

20-29

30-39
0.36

0.21

0.40

0.26

0.48

0.29

0.47

0.29

Labor Supply

\begin{tabular}{rllll} 
Single Men & & & & \\
$20-29$ & 0.41 & 0.42 & 0.33 & 0.42 \\
$30-39$ & 0.33 & 0.34 & 0.27 & 0.34 \\
Single Women & & & & \\
$20-29$ & 0.24 & 0.29 & 0.24 & 0.28 \\
$30-39$ & 0.20 & 0.22 & 0.20 & 0.25 \\
Married Men & & & & 0.49 \\
$20-29$ & 0.48 & 0.49 & 0.46 & 0.18 \\
$30-39$ & 0.47 & 0.46 & 0.45 & 0.19 \\
Married Women & & & & \\
$20-29$ & 0.13 & 0.18 & 0.10 & \\
\hline $30-39$ & 0.13 & 0.25 & 0.10 & \\
\hline
\end{tabular}

Experiment 1 is the case where we introduce the returns to experience for women

Experiment 2 is the case where we eliminate the gender gap 
Table 10: People can have kids only in one period

Only in the First Period

Statistics

No returns to

Experiment 1

Only in the Second Period

exp. for women

No returns to

Experiment 1

exp. for women

Timing of Births

$\%$ of kids born after age 30

0

1

1

Marital Status of Population

$\begin{array}{rrccc}\text { married }(\%) & 59 & 56 & 55 & 58 \\ \text { single (\%) } & 41 & 44 & 458 & 42\end{array}$

Fertility

$\begin{array}{lllll}\text { TFR } & 1.59 & 1.41 & 1.62 & 1.58\end{array}$

Income Inequality Income of single females
income of married females

20-29

30-39

0.45

0.44

0.31

0.36

0.27

0.35

0.22

0.25

Labor Supply

$\begin{array}{rllll}\text { Single Men } & & & & \\ 20-29 & 0.46 & 0.44 & 0.48 & 0.48 \\ 30-39 & 0.36 & 0.34 & 0.39 & 0.38 \\ \text { Single Women } & & & & 0.37 \\ 20-29 & 0.27 & 0.35 & 0.31 & 0.24 \\ 30-39 & 0.27 & 0.32 & 0.22 & 0.52 \\ \text { Married Men } & & & & 0.50 \\ 20-29 & 0.51 & 0.53 & 0.50 & \\ 30-39 & 0.53 & 0.53 & 0.48 & 0.45 \\ \text { Married Women } & & & & 0.20 \\ 20-29 & 0.15 & 0.24 & 0.41 & 0.18 \\ 30-39 & 0.16 & 0.19 & & \end{array}$

